\title{
Imaging biomarkers in neurodegeneration: current and future practices
}

\author{
Peter N. E. Young ${ }^{1}$, Mar Estarellas², Emma Coomans ${ }^{3}$, Meera Srikrishna', Helen Beaumont ${ }^{4}$, Anne Maass ${ }^{5}$, \\ Ashwin V. Venkataramann ${ }^{6,7}$, Rikki Lissaman ${ }^{8}$, Daniel Jiménez ${ }^{9,10}$, Matthew J. Betts ${ }^{5,11}$, Eimear McGlinchey ${ }^{12}$, \\ David Berron ${ }^{13}$, Antoinette O'Connor ${ }^{9}$, Nick C. Fox ${ }^{9}$, Joana B. Pereira ${ }^{13,14}$, William Jagust ${ }^{15,16}$, Stephen F. Carter ${ }^{17,18}$, \\ Ross W. Paterson ${ }^{9+}$ and Michael Schöll ${ }^{19,19^{*+}}$
}

\begin{abstract}
There is an increasing role for biological markers (biomarkers) in the understanding and diagnosis of neurodegenerative disorders. The application of imaging biomarkers specifically for the in vivo investigation of neurodegenerative disorders has increased substantially over the past decades and continues to provide further benefits both to the diagnosis and understanding of these diseases. This review forms part of a series of articles which stem from the University College London/University of Gothenburg course "Biomarkers in neurodegenerative diseases". In this review, we focus on neuroimaging, specifically positron emission tomography (PET) and magnetic resonance imaging $(\mathrm{MRI})$, giving an overview of the current established practices clinically and in research as well as new techniques being developed. We will also discuss the use of machine learning (ML) techniques within these fields to provide additional insights to early diagnosis and multimodal analysis.
\end{abstract}

Keywords: Neurodegenerative diseases, Neuroimaging, PET, MRI, Alzheimer's disease, Machine learning, dementia

\section{Introduction}

Neurodegenerative diseases, including Alzheimer's disease (AD), are now recognised to start years before symptoms appear [1]. Studies of the genetically caused familial $\mathrm{AD}$ have proposed a sequence of pathologic events, starting with build-up and accumulation of amyloid- $\beta(A \beta)$, that can now be measured in the brain (using positron emission tomography (PET) imaging) and in cerebrospinal fluid (via lumbar puncture) and ending with cognitive deficits and dementia [2]. These events appear to start demonstrating abnormalities in a distinct order, but also overlap temporally.

\footnotetext{
* Correspondence: michael.scholl@neuro.gu.se

${ }^{\dagger}$ Ross W. Paterson and Michael Schöll contributed equally to this work. 'Wallenberg Centre for Molecular and Translational Medicine and the Department of Psychiatry and Neurochemistry, University of Gothenburg, Sahlgrenska University Hospital, Gothenburg, Sweden

${ }^{9}$ Dementia Research Centre, UCL Institute of Neurology, University College London, London, UK

Full list of author information is available at the end of the article
}

Specifically considering $\mathrm{AD}$, the National Institute on Ageing and Alzheimer's Association (NIA-AA) has developed the research framework for the diagnosis of $\mathrm{AD}$ [3]. This categorises diagnoses into the $\operatorname{AT}(\mathrm{N})$ scale, referring to $A \beta$, tau and neurodegeneration. These three pathologies can all be (spatially and temporally) identified in vivo with current imaging biomarkers. Further biomarkers that could be added to contribute to the ATN categories (as discussed in detail in [3]) could come from the imaging modalities discussed in this review. Further refinement of diagnostic cut-offs for each of these imaging-derived biomarkers will then also provide increases in the sensitivity and specificity for the respective modality.

Neuroimaging has become a standard tool in the clinical work up of individuals suspected of having a neurodegenerative disease. The use of various magnetic resonance imaging (MRI) techniques and the development of novel PET ligands have led to the ability to 
understand these diseases in vivo like never before. Access to these tools has provided access to a plethora of objective measures which can indicate both the presence and progression of these diseases. This is useful for patients in a clinical setting but can also be used for the targeted recruitment to clinical treatment trials and tracking of any treatments that are undergoing clinical trial both in terms of efficacy of treatment but also for safety monitoring. Neurodegenerative disorders are increasingly requiring the input of multiple disciplines for both the diagnosis and understanding of these diseases, and imaging biomarkers have a role to play in the wider collaborative approach to understanding these diseases as well.

There have been considerable advances in the portfolio of PET ligands available for use in identifying biomarkers associated with neurodegeneration, some of which have progressed to use in the clinic and others present promising new avenues for understanding these neurodegenerative diseases. MRI techniques are also being used to help with both the diagnosis and the development of our understanding, with structural MRI still being the most widely available imaging tool for neurodegeneration. This review article will give a brief overview of the established and upcoming practices both within the PET and MRI fields in relation to neurodegeneration as well as how machine learning can be an aid to these modalities.

\section{Positron Emission Tomography [18F]FDG PET}

[18F]-2-Fluoro-2-deoxy-D-glucose (FDG) was first introduced as a PET tracer for neuroimaging in 1979 [4] and has since been established as a routine research and clinical biomarker for diagnosing dementia [5]. Glucose is the brain's main source of energy. It circulates in the blood and crosses the blood-brain barrier. When energy is needed, glucose is phosphorylated as the first step of energy being made available. FDG is an artificial analogue of glucose, which mimics glucose's action until it is phosphorylated. Phosphorylated FDG gets trapped in tissue and is not metabolised further. The rate of FDG trapping is proportional to glucose metabolism. Rocher et al. showed that regional glucose consumption is related to synaptic activity [6], and decreased regional FDG trapping (hypometabolism) is interpreted as a sign of synaptic and neuronal damage.

Protocols for acquiring FDG images can vary between sites. After intravenous injection of FDG into a fasting subject (fasted for $\sim 4 \mathrm{~h}$ ), and waiting a minimum of 30 min to allow FDG to circulate, PET data is acquired, typically for 10-30 min. Absolute glucose metabolism can be calculated by using an arterial input function derived from arterial blood, but more commonly the standardised uptake value (SUV) is calculated using body mass $(\mathrm{kg})$ and injected dose of FDG $(\mathrm{MBq})$. Regional SUV ratios (SUVRs) can be generated using a standard reference region, normally a region unaffected by the disease process, e.g. the grey matter of the cerebellum in $\mathrm{AD}$ [7].

Clinical application of FDG PET varies between countries, but regional neocortical hypometabolism is accepted to be useful to help differentiate dementias even though regional patterns can overlap [8-10]. In $\mathrm{AD}$, hypometabolism can appear before visible atrophy [11] and a symmetrical hypometabolism in the temporoparietal, posterior cingulate and medial temporal cortices is usually seen. Reported sensitivity and specificity for $A D$ diagnosis vary from study to study, but in 2015, Smailagic et al. [12] found the sensitivity for conversion from mild cognitive impairment (MCI) to $\mathrm{AD}$ was $76 \%$ at $82 \%$ specificity. In frontotemporal dementia, hypometabolic regions include the frontal and anterior temporal lobes, cingulate gyri, uncus, insula, basal ganglia and medial thalamus. The hypometabolism is often asymmetric [13] with sensitivity of $88 \%$ and specificity of $91 \%$. Occipital hypometabolism occurs in both posterior cortical atrophy (an atypical form of $\mathrm{AD}$ ) and dementia with Lewy bodies (DLB) [14]: dopamine transporter imaging could be used to differentiate these dementia types since dopamine transport is decreased in DLB.

While useful, FDG PET has limitations. Decreased uptake can be caused by a diminished cerebrovascular circulation or by metabolic disorders such as diabetes rather than decreased synaptic activity [15]. As the scan involves radiation exposure, it is not recommended to be repeated more frequently than annually. The PET process itself (isotope production, radiochemistry, scan) is expensive compared to MRI, and [18F] has a short half-life of just under $2 \mathrm{~h}$ (110 min), which adds time pressure to scans. In summary, FDG PET is a useful biomarker for investigating neuronal injury in dementia.

\section{Amyloid- $\beta$ PET}

The involvement of $A \beta$ in the pathological expression of $\mathrm{AD}$ has been known for over 25 years [16]. This involves the aggregation of fibrillar $A \beta$ causing the creation of socalled $A \beta$ plaques in the brain [17]. The current hypothesis is that plaque accumulation induces multiple downstream alterations that lead to neurodegeneration and cognitive decline. Our understanding of these downstream alterations has changed over the years and now includes not only inflammation but synaptic alterations, functional changes and alterations in tau $[18,19]$. Historically, the only way to definitively classify a person as having AD was through post mortem examination of their brain tissue for $A \beta$ plaques and neurofibrillary tangles (NFTs) predominantly consisting of 
hyperphosphorylated tau protein. With the advent of $A \beta$ PET tracers, it is now possible to have an in vivo, quantifiable measure of a key biomarker of $\mathrm{AD}$, thereby allowing a possible diagnosis much earlier [20]. $A \beta$ in the brain displays a pattern of deposition that begins in medial frontal and basal temporal areas, progressing to include the neocortex, primary sensory-motor areas and finally the MTL and striatum [21-23].

The first $A \beta$-specific PET tracer introduced to provide accurate imaging data of $A \beta$ pathology is Pittsburgh compound B (PiB) labelled with C-11 [24, 25]. The compound is derived from thioflavin- $\mathrm{T}$ and is known to have a high affinity to the $A \beta$ plaques. This has resulted in its widespread use both as a diagnostic tool and as a reference for other A $\beta$ PET tracers [25]. While [11C]PiB is useful in research settings, its widespread utility is limited by the short half-life of C-11 necessitating a local cyclotron and radiochemistry. Therefore, the development of an F-18 (110-min half-life)-based $A \beta$ tracer was required for routine clinical use as those can be delivered from an off-site cyclotron. There are currently three F-18-labelled $A \beta$ PET tracers approved by the FDA and EMA for clinical use. These are [18F]flutemetamol, [18F]florbetapir and [18F]florbetaben. These tracers have shown to behave similarly to $\mathrm{PiB}$ in head-to-head studies [26-28], and some have been verified histologically [29]. Another A $\beta$-specific tracer, [18F]NAV4694, is thought to overcome some of the reported shortcomings of the previous-generation tracers, mainly "offtarget" binding [30]. The range of tracers being used, all with differing uptake characteristics and varying pharmacokinetics, means that care must be taken when performing analyses. Each of these tracers will require their own analysis pipeline with possible differences in reference regions [31, 32]. Cut points for A $\beta$ positivity will also vary between tracers [33]. This is why there has been an ongoing development to standardise quantitative $A \beta$ imaging measures using the "centiloid scale" [34]. Work is now ongoing to validate centiloid scaling between various tracers and against other biomarkers [35-37]. Standardisation such as centiloid scaling has yet to be applied in tau imaging to a greater extent [38].

As post mortem and in vivo biomarker evidence closely associate $A \beta$ pathology with $A D, A \beta$ PET tracers have become standard tools for clinicians to aid in their diagnosis of patients suspected of having $\mathrm{AD}$ [39]. These tracers also have a key place in AD research in differentiating diagnostic groups and tracking disease progression [40]. In addition, these tracers are readily used for the evaluation of therapeutic trial outcomes to examine the effects of drugs removing brain $A \beta[41,42]$.

\section{Tau PET}

The advent of tau-specific PET tracers has marked the beginning of a new era with potential applications in differential diagnosis and prognosis and serving as a secondary outcome measure for clinical trials [43]. Tau is physiologically involved in the stabilisation of microtubules and can present with three or four repeat $(3 R / 4 R)$ microtubule-binding domains [44, 45]. First-generation tau PET ligands all seem to bind mixed 3R/4R paired helical filament (PHF) formations of tau [46-50] and include [11C]PBB3, a series of "THK" tracers ([18F]THK523, [18F]THK5105 and [18F]THK5351), and [18F]flortaucipir (formerly [18F]T807 or [18F]AV1451) [51-53]. As these "first-generation" tracers face challenges such as off-target binding, novel tau compounds have been developed, though their relationship with clinical outcome measures has yet to be established in larger cohorts [54, 55]. Notable "second-generation" tau ligands include [18F]RO948, [18F]GTP1, [18F]PI2620, [18F]PM-PBB3 and [18F]MK6240 [54, 56-60], which have shown reduced off-target binding with similar ontarget signal response [61, 62]. As currently available tau PET ligands bind AD-like mixed 3R/4R tau pathology, the utility of tau PET in pure $3 \mathrm{R}$ or $4 \mathrm{R}$ tauopathies, such as progressive supranuclear palsy and corticobasal degeneration, has shown to be less persuasive [57]. So far, tau PET studies in clinical settings have mostly been performed within the field of AD using the [18F]flortaucipir tracer (see Fig. 1).

In $\mathrm{AD}$, tau PET imaging studies have demonstrated that tau deposition seems to follow the staging pattern revealed by Braak and Braak, suggesting tau spreads from the entorhinal cortex (Braak I/II) to the inferolateral temporal and medial parietal lobes (Braak III/IV) and finally the neocortex (Braak V/VI) [63-65]. This vulnerability of brain regions for tau pathology overlaps with brain regions underlying the different clinical phenotypes in typical and atypical AD dementia and correlates with atrophy and reduced glucose metabolism in those regions, a relationship that is not found with $A \beta$ $[66,67]$. Tau pathology in Braak I/II is also commonly observed in cognitively unimpaired controls, which likely reflects an age-related process of tau accumulation. Also, in these cognitively unimpaired individuals, tau seems to be associated with regional atrophy and hypometabolism, as well as to subtle cognitive deficits [68-73]. Furthermore, a recent longitudinal study has shown that both baseline and change in [18F]flortaucipir are related to changes in cognition [74]. Hence, both the amount and distribution of tau PET accurately reflect cognitive symptoms and deterioration. The clinical utility of tau PET has recently been demonstrated in a multi-centre study highlighting the ability of [18F]flortaucipir to discriminate between $\mathrm{AD}$ dementia and non- $\mathrm{AD}$ 


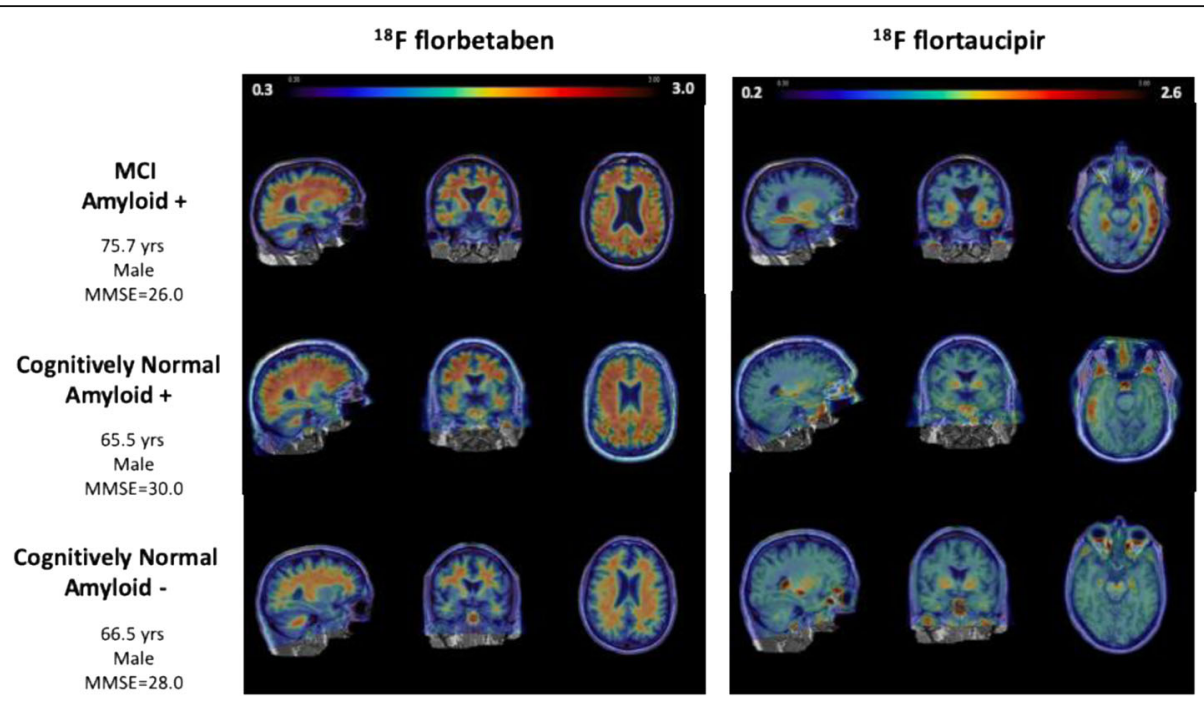

Fig. 1 Comparison of [18F]florbetaben and [18F]flortaucipir for three patients. The authors would like to acknowledge Dr. Susan Landau (UC Berkeley) for her assistance in the creation of this figure. Scale is standardised uptake value ratio (SUVr)

neurodegenerative diseases, with highest sensitivity (96.8\%) and specificity (87.9\%) using several thresholds applied to temporal and temporoparietal regions [75]. Furthermore, while tau PET and tau measured in the cerebrospinal fluid (CSF) performed equally well in separating prodromal AD from controls, tau PET outperformed tau-CSF in discriminating prodromal AD from AD dementia [76].

Although tau PET imaging shows great potential for implementation into the clinic, the high regional specificity of tau requires careful selection of regional and global measures for categorising individuals into taupositive or tau-negative as suggested by the NIA-AA research framework. Different cut points for tau-tracer binding in different brain regions have been suggested, however, standardisation of such methodological aspects is needed. Furthermore, although the majority of $\mathrm{AD}$ patients present with both high $A \beta$ and high tau burden, studies have shown that some $\mathrm{AD}$ patients present with high $A \beta$ and low tau burden [77-79]. Possible explanations such as clinical misdiagnoses (with incidental $A \beta$ co-pathology) or differences in tau conformations that might affect tracer binding are to be examined in future clinical tau PET studies and studies using novel tau PET ligands. Importantly, although the advent of tau PET tracers has greatly advanced our knowledge regarding the close relationship between tau pathology and downstream neurodegeneration events linked to cognitive decline, it remains as of yet unknown how $A \beta$ relates to the development of tau, and how tau relates to the occurrence of neurodegeneration. A study by Jacobs and colleagues indicated that $A \beta$ may facilitate the spread of tau from the medial temporal lobe to the downstream posterior cingulate cortex through the parahippocampal cingulum [80]. Ideally, multimodal longitudinal imaging studies are needed to elucidate the temporal relationships between pathology biomarkers.

\section{SV2A PET}

In $A D, A \beta$ and tau alongside neuroinflammation and vascular insufficiency lead to irreversible synaptic dysfunction and loss [81] causing the deleterious amnestic presentation of the disease. Loss of synapses and decreased synaptic density (particularly the vulnerable hippocampus/medial temporal lobe) are likely earlier events than neurodegeneration and important for drug targets. Previously, synaptic density changes could only be studied cross-sectionally from post mortem brain tissue or biopsy [82, 83]. Recently, these changes have been able to be visualised directly in vivo in humans [84].

PET ligands targeting the synaptic vesicle glycoprotein 2A (SV2A) form a potentially useful and exciting investigative tool to measure synapses [85]. SV2 is a 12 transmembrane domain integral protein with three isoforms (2A, $2 \mathrm{~B}$ and $2 \mathrm{C})$. SV2A is the most ubiquitous and is expressed as a transmembrane glycoprotein in secretory vesicles on presynaptic terminals. It is critical to synaptic function, particularly $\mathrm{Ca} 2+$-dependent exocytosis [86], and is known to be the binding site of levetiracetam [87].

[11C]UCB-J is a PET ligand developed to image SV2A with favourable brain uptake, kinetics and dosimetry shown in non-human primates [88]. There is a high correlation between in vitro SV2A UCB-J binding and in vitro synaptophysin density $\left(r^{2}=0.90\right.$ for GM regions) pre-clinically [4]. [11C]UCB-J has a high affinity for SV2A $(\mathrm{Ki}=7 \mathrm{~nm})$ and has been successfully displaced by levetiracetam in vivo in humans, with good dosimetry 
(4.5 mSv/MBq) [4]. Regional time-activity curves showed [11C]UCB-J has fast kinetics, was well described by a 1 tissue compartment model (1TC) or a simplified reference tissue model (SRTM) (reference centrum semiovale) and had a 3-9\% mean test-retest variability in VT across regions [89].

Decreased [11C]UCB-J binding was first shown in a small disease group with temporal lobe epilepsy and mesial temporal sclerosis $(n=3)$, revealing region-specific unilateral decreases in the hippocampus [84]. The first study in MCI/AD using [11C]UCB-J compared A $\beta+$ patients $(n=10)$ with age-matched $\mathrm{A} \beta-$ controls and showed a significant reduction in hippocampal SV2A binding (41\% decrease in $\left.\mathrm{BP}_{\mathrm{ND}}\right)$ that survived partial volume correction and correlated significantly with episodic memory [89]. The decrease in SV2A binding throughout the neocortex in MCI/AD was modest and not significantly different from controls.

Multiple other candidates selective to SV2A have been developed including [18F]UCB-H, which displays a comparatively good signal but higher variability than [11C]UCB-J [90] and a human dosimetry of $19.7 \mathrm{mSv} / \mathrm{MBq}$ [91]. The longer [18F] half- life allows wider use and more time for transit to clinical/ research sites [92].

Much future work involving SV2A imaging in AD remains. Currently, the first published AD study needs replication with more patients alongside longitudinal investigation. The relationship of SV2A binding with $A \beta /$ tau needs to be explored as well as its relationship with other disease features such as mitochondrial dysfunction, cellular stress and glial (microglial and astrocyte) reactivity. A summary of discussed PET imaging can be found in Table 1.

\section{Magnetic Resonance Imaging Structural MR imaging}

Structural imaging is the imaging workhorse of neurodegeneration, it is the most widely used and accessible, it is recommended in diagnostic guidelines [101] and it forms part of most consensus criteria. Structural MRI (sMRI) has several advantages over computed tomography $(\mathrm{CT})$. Its main uses are (a) excluding brain lesions, (b) determining patterns of atrophy and (c) assessing vascular burden. Research key aims include improving early diagnosis and tracking disease progression.

Table 1 Summary table of typical PET tracers for neurodegeneration-related investigations discussed in this article

\begin{tabular}{|c|c|}
\hline Example tracers & Protocol \\
\hline $\begin{array}{l}\text { Glucose } \\
\text { metabolism: } \\
\text { [18F]FDG }\end{array}$ & $\begin{array}{l}\text { - Fasting for } \sim 4 \mathrm{~h} \\
\text { - Scanning } 30 \text { min after injection } \\
\text { - Scan typically for 0-30 min }\end{array}$ \\
\hline $\begin{array}{l}\text { A : } \\
\text { [11C]PiB } \\
\text { [18F]Florbetaben } \\
\text { [18F]Florbetapir } \\
\text { [18F]Flutametamol } \\
\text { [18F]NAV4694 }\end{array}$ & $\begin{array}{l}\text { Scan protocols vary between tracers; } \\
\text { however, typically, patients are scanned } \\
40-60 \text { min (PiB) or } 70-90 \text { min (most [18F]- } \\
\text { based tracers) after injection for } \sim 20 \text { min. } \\
\text { For EANM clinical guidelines, see } \\
\text { Minoshima et al. [94] }\end{array}$ \\
\hline
\end{tabular}

Tau:

[18F]THK5351

[18F]THK5317

[18F]THK523

[11C]PBB3

[18F]Flortaucipir

[18F]RO948

[18F]MK6240

[18F]GTP1

[18F]PI2620

Analysis
- SUV using weight and injected dose
- SUVR using cerebellar grey matter or pons
as reference regions [7]

Typical analysis will use SUVR using the cerebellum or cerebellar grey matter as the reference region [21, 31, 32] Limitations

- Hypometabolic patterns overlap

between multiple neurodegenerative diseases [8-10]

- Still not enough evidence to support routine clinical use in the prodromal phase [93]

- [C11]PiB requires an on-site cyclotron

- Second-generation tracers have certain off-target binding issues as well as reduced uptake in the cortex as compared to PiB [30]

- Latest generation tracers have yet to be validated in larger cohorts - A $\beta$ positivity can refer to various neurodegenerative diseases [95]

Most typical analyses will derive SUVR using the cerebellum, cerebellar grey matter or inferior cerebellum/cerebellar grey as the reference region [96].
- Molecular diversity of tauopathies means no single tau tracer can be used for all disorders [57]

- First-generation tracers exhibit offtarget binding and subcortical white matter uptake $[96,97]$

- Second-generation ligands have yet to be evaluated with regard to clinical outcomes in larger cohorts [54, $55,96]$

- Experimental and clinical validation of tau tracers in general is still required $[98,99]$

- Requires replication with more patients alongside longitudinal investigation [84, 89]

- Association with other disease features (as described above) needs to be explored 


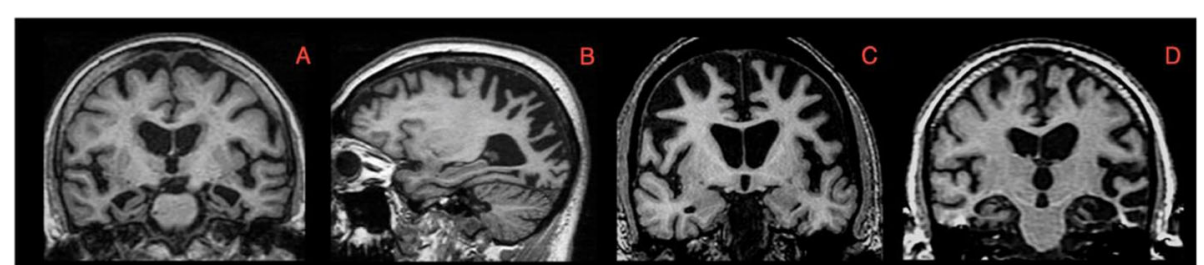

Fig. 2 T1-weighted MRI scans demonstrating characteristic cortical atrophy signature in selected diseases: a typical amnestic Alzheimer's disease, b posterior cortical atrophy, $\mathbf{c}$ behavioural variant frontotemporal dementia and $\mathbf{d}$ semantic dementia

\section{Atrophy patterns-signatures of neurodegeneration}

Neurodegenerative disorders, to a greater or lesser extent, show characteristic patterns or signatures of brain atrophy on T1-weighted images (see Fig. 2) that can be used to improve differential diagnosis. Table 2 outlines some of the most common and useful atrophy patterns for the diagnosis of these diseases. Specific brain signatures have also been described in young onset AD [102, 103] and genetically mediated forms of frontotemporal dementia [104-106].

It is also important to mention the utility of white matter hyperintensities (WMH) as these are essential for the diagnosis of cerebral small vessel disease (CSVD) [107]. Moreover, the location of microbleeds seen with T2\%/SWI sequences can often bring diagnostic clarity on the underlying pathology-microbleeds associated with hypertension are found in deep brain regions, whereas $A \beta$-related microbleeds are more likely cortical [108]. Finally, diffusion-weighted imaging is the most sensitive sequence in the diagnosis of sporadic Creutzfeldt-Jakob disease [109].

\section{Current use of structural MRI in research}

Voxel-wise analyses confirm the value of brain atrophy patterns in pathologically distinct dementias [117-119]. In $\mathrm{AD}$, volume loss appears later than $\mathrm{A} \beta$ deposition and synaptic dysfunction [120], but hippocampal changes are detected before symptoms [121]. Furthermore, hippocampal volume has been validated and accepted by regulatory agencies as a biomarker for trials targeting predementia stages [122]. Longitudinal rates of atrophy monitor progression and can change the sample size needed to show treatment effects depending on the technique and selected anatomical region [123, 124].

Cortical thickness has also been shown to be a marker of $\mathrm{AD}$, where regionally specific cortical thinning can be used to detect presymptomatic A $\beta$-positive individuals but also can indicate the severity of symptoms $[125,126]$. It has also been shown to be able to differentiate between neurodegenerative disorders, for example between $\mathrm{AD}$ and FTD [127]. Shape analysis can also be used in differentiating individuals, studies of hippocampal shape changes and atrophy have demonstrated differences in the substructural changes of the hippocampus

Table 2 Atrophy patterns included in the current diagnostic criteria of selected neurodegenerative dementias. Only changes in T1weighted MRI sequence are included in the MRI signature column. The MRI signatures described are supportive features for the diagnosis unless otherwise stated. PPA primary progressive aphasia. FTD frontotemporal dementia

\begin{tabular}{|c|c|c|}
\hline Disease & Diagnostic criteria & MRI signature \\
\hline Alzheimer's disease & McKhann et al. [110] & $\begin{array}{l}\text { Disproportionate atrophy in the medial, basal and lateral temporal lobe and medial parietal } \\
\text { cortex }\end{array}$ \\
\hline Posterior cortical atrophy & Crutch et al. [111] & Predominant occipito-parietal or occipito-temporal atrophy ${ }^{a}$ \\
\hline Logopenic variant PPA & $\begin{array}{l}\text { Gorno-Tempini et al. } \\
\text { [112] }\end{array}$ & Predominant left posterior perisylvian or parietal atrophy \\
\hline Behavioural variant FTD & Rascovsky et al. [113] & Frontal and/or anterior temporal atrophy \\
\hline Semantic variant PPA & $\begin{array}{l}\text { Gorno-Tempini et al. } \\
\text { [112] }\end{array}$ & Predominant anterior temporal lobe atrophy \\
\hline Non-fluent variant PPA & $\begin{array}{l}\text { Gorno-Tempini et al. } \\
\text { [112] }\end{array}$ & Predominant left posterior fronto-insular atrophy \\
\hline Dementia with Lewy bodies & McKeith et al. [114] & Relative preservation of the medial temporal lobe structures ${ }^{\text {b }}$ \\
\hline Multiple system atrophy & Gilman et al. [115] & Atrophy of the putamen, middle cerebellar peduncle, pons or cerebellum \\
\hline $\begin{array}{l}\text { Progressive supranuclear } \\
\text { palsy }\end{array}$ & Höglinger et al. [116] & Atrophy predominant in the midbrain relative to pons \\
\hline
\end{tabular}


depending on the type of neurodegenerative disorder [126, 128]. Shape analysis of brain ventricles has also shown that markers such as perimeters of the ventricles can be simple markers extracted from sMRIs to differentiate $\mathrm{HC}$ and $\mathrm{AD}$ [129].

\section{Future directions of research}

High-resolution volumetry of the medial temporal lobe in AD using 7T MRI High spatial resolution sMRI now allows for volumetry of hippocampal subfields [130, 131]. Early changes in CA1 have been observed in AD, with volumetric studies indicating that CA1 atrophy measures may improve diagnostic accuracy at the MCI stage (see [120] for a review). Other studies, however, have found that the subiculum is associated with poorer cognitive performance and risk of developing dementia [132] and may serve as an early marker of AD-related atrophy [133]. Recent studies of volume, thickness and shape measurements of extrahippocampal subregions in the medial temporal lobe have shown that thickness measurements of the transentorhinal region could differentiate $A \beta$ positive from negative individuals while outperforming other measures such as CA1 or whole hippocampal volume [134].

\section{Assessment of iron deposition using in vivo MRI}

Novel MRI techniques, such as quantitative susceptibility mapping (QSM) or the $\mathrm{T} 2 *$ transverse relaxation time, have shown that iron levels and its rate of accumulation are heterogeneous in the human brain [135] and correlates with cognitive impairment $[136,137]$ and slowing of motor performance [138, 139]. Abnormal iron deposition has been reported in AD [140, 141], Parkinson's disease (PD) (for a review see [142]), multiple sclerosis $[143,144]$ and additional neurodegenerative disorders (for a review see [145]). The elevation in cortical iron deposition in PD is concordant with known alphasynuclein pathology [146] and in $\mathrm{AD}$, has been shown to predict cognitive decline in individuals with $A \beta$ pathology [147].

Taken together, in vivo sMRI techniques may have the potential to improve early and differential diagnosis, aid stratification of patients into clinical trials and track disease progression in neurodegenerative disorders.

\section{Functional MRI, ASL, DTI and graph theory Functional MRI}

Neuronal dysfunction and altered connectivity of distinct brain networks are thought to occur early in the course of neurodegenerative diseases and can be measured indirectly with functional magnetic resonance imaging (fMRI). In $\mathrm{AD}$, several resting-state fMRI studies revealed altered connectivity in the default mode network
[148, 149], ranging from hippocampal coactivation [150] to potential compensatory increased activation in the MTL [151]. Studies have also suggested distinct atrophy patterns within various intrinsic functional networks for a number of neurodegenerative diseases [152]. Taskbased fMRI studies are less consistent and have often reported increased task activation or reduced deactivation in hippocampus, frontal and parietal regions in the presence of $\mathrm{AD}$ pathology or in patients with $\mathrm{MCI}$ (e.g. [153-158]). There are also data indicating that an initial phase of hyperactivation [159] is followed by hypoactivation with further increasing $A \beta$ burden and disease progression [160, 161]. Whether task-based fMRI shows hyper- or hypoactivation likely depends on the specific fMRI contrast/task, the brain region examined, and the pathological stage of an individual (for an example see Fig. 3). While task-based fMRI is a promising future biomarker, sensitivity and reliability of different fMRI tasks within-subject and across cohorts still need to be established.

\section{Arterial Spin Labelling}

Current models of AD suggest that metabolic alterations occur in the brain before structural changes could be identified. FDG PET (as discussed earlier) has been a standard tool for measuring these changes in the past; however, due to the introduction of tau and $\mathrm{A} \beta$-specific PET tracers (as discussed previously), there is increased demand for a biomarker that does not require a second PET scan. Arterial spin labelling (ASL) has shown to be a promising replacement for FDG PET; this is due to the metabolism and perfusion in the brain being very closely matched [162] and so hypometabolic patterns seen in FDG PET can be equally seen in ASL images. This fact coupled with patients already undergoing an MRI scan means that ASL could serve as a cheaper and faster alternative which would also reduce the radiation burden to the patient without sacrificing any diagnostic quality for both AD and FTD [163, 164]. For both AD and other neurodegenerative diseases, there is still a requirement for larger studies to validate this technique $[163,165]$.

\section{DTI}

The brain's white matter tracts are also sensitive to the underlying pathology of neurodegenerative disease [166, 167]. Using diffusion tensor imaging (DTI), a variant of MRI that is sensitive to the mobility of water molecules in tissue, it is possible to quantify the microstructural properties of white matter tracts in vivo [168]. In AD, DTI studies have identified microstructural alterations (specifically increased absolute diffusivities and reduced fractional anisotropy) in tracts linking regions affected early by disease pathology, including the fornix, parahippocampal cingulum and corpus callosum [169-171]. 


\section{Increased tau burden relates to increased task activation}
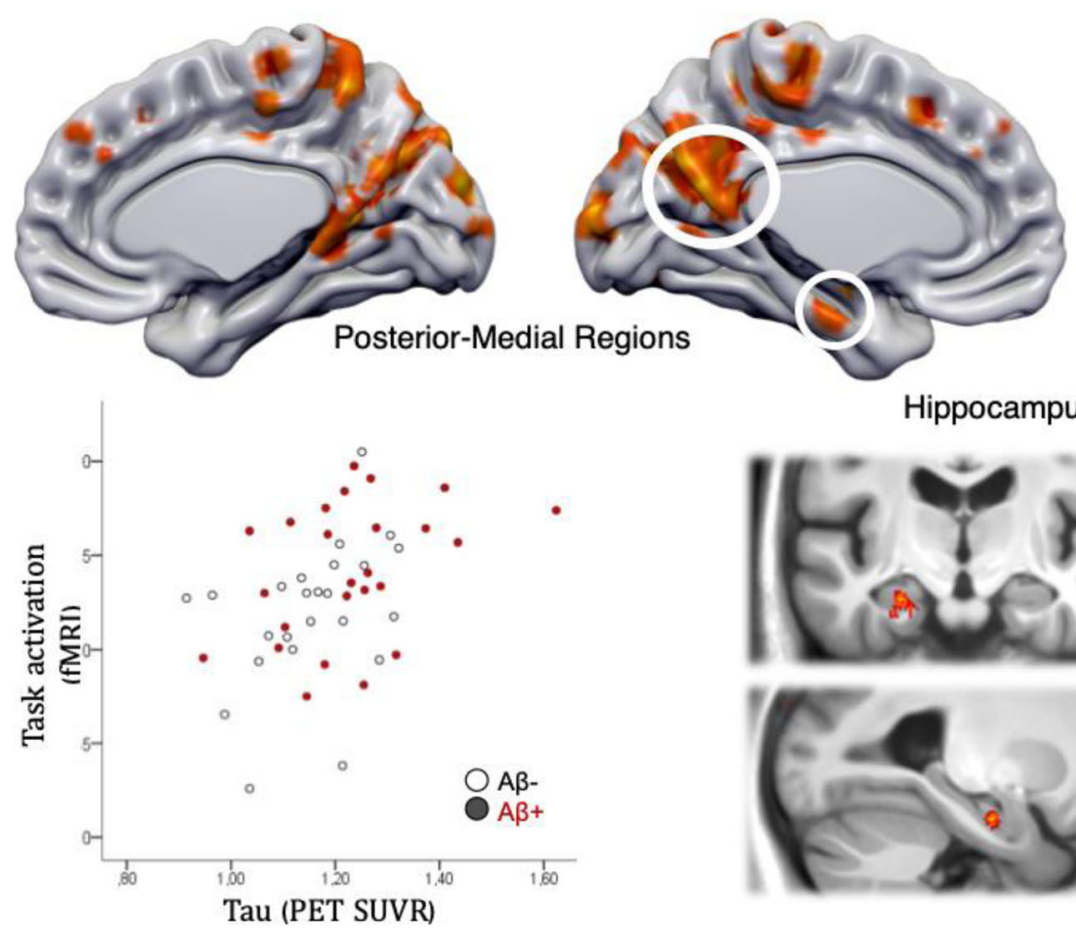

Hippocampus

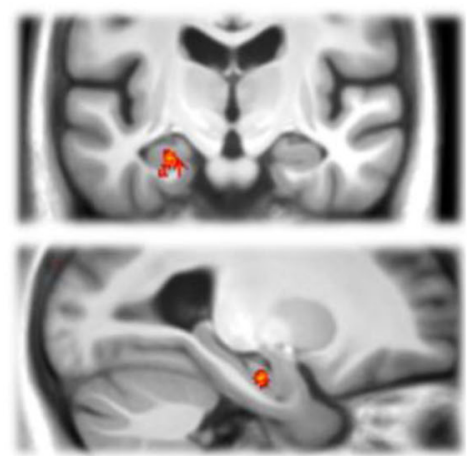

Fig. 3 Cognitively normal older adults $(n=49)$ underwent 3-T fMRI while performing a mnemonic discrimination task as well as PET imaging. A whole-brain multiple regression showed that increased tau burden (mean flortaucipir SUVR from Braak III/IV ROI) was related to increased task activation during object processing (covarying for age and gender). Tau-related activation increases were seen mainly in hippocampus and posterior-medial regions. Results are FDR-corrected at the cluster level ( $p_{\text {cluster }}<.05, p_{\text {voxel }}<.001$ uncorrected). The scatter plot (lower left) shows the correlation of regional Flortaucipir SUVR and object activation in posterior-medial regions. See Maass et al. [158] for study details

Microstructural variation in these tracts has also been associated with the accumulation of $A \beta$ and tau in cognitively normal individuals [80, 172], suggesting that DTI may prove useful as a biomarker for AD. Similarly, alterations in diffusivity have been described in presymptomatic and early-stage familial frontotemporal dementia. Individuals suffering from amyotrophic lateral sclerosis (ALS) were also seen to have increased diffusivity in the bilateral centrum semi-ovale as well as deep and parietal white matter [173]. However, common DTI measures such as fractional anisotropy are influenced by numerous disease-relevant properties, including myelination, thereby limiting anatomical specificity [174]. Thus, while DTI has proven to be useful as a tool for understanding neurodegenerative conditions, further research is needed to establish its utility as a biomarker.

\section{Graph theory}

Graph theory is the study of systems of interactive elements-'nodes', and the connections between them'edges' [175, 176], allowing for representation of brain networks. Both structural (DTI) and functional connectivity measures (fMRI) can be obtained from brain graphs
$[177,178]$. AD research uses graph theory to examine integration (path length between nodes), segregation (clustering) and centrality (importance of nodes in a network) [179]. Network topology appears to be disrupted, with clinical symptoms arising from changes in communication between anatomically and functionally connected brain areas [179]. AD appears to result in longer paths between nodes with lower global efficiency [179] and with less interconnectivity and more segregated clusters in the default mode network (DMN) [180]. Widespread changes within and outside the DMN are seen with advanced $A \beta$ accumulation [181]. Inconsistent findings between $\mathrm{AD}$ studies may be due to different definitions of nodes and edges [182]. Harmonisation is needed for future work.

\section{Machine learning}

Current reviews of ML algorithms applied to neurodegenerative disorders include a systematic review of the use of ML and neuroimaging in general to assist the diagnosis of dementia $[183,184]$ to more methodological reviews, focusing on feature extraction, different ML architectures and validation techniques [185-187]. Three 
longitudinal studies analysed the progression of $\mathrm{AD}$ [188-190] using structural MRI and deep learning (DL) algorithms such as recurrent neural networks (RNNs) and variations of long short-term memory networks (LSTMN). The most common feature in order to study disease progression is hippocampal volume.

\section{Early diagnosis and progression to $\mathrm{MCl} / \mathrm{AD}$}

The majority of ML studies are focused on diagnosis or early detection of AD [191-213]. There has been an increasing effort to try to fully predict $\mathrm{AD}$ from $\mathrm{MCI}$ or healthy controls as well as using artificial intelligence techniques (such as ML or DL) in order to aid clinical diagnosis. Lately, more importance has been given to subject memory complaints (SMC) as it could be a preasymptomatic stage of MCI.

There are several longitudinal databases that are helping to develop these kinds of studies such as ADNI, OASIS or the Rotterdam Study. With this increase of data, there has been a shift from the use of ML algorithms such as support vector machines (SVMs) and $k$ nearest neighbours (KNN) to more DL-based studies, mostly convolutional neural networks (CNNS) [205, 214, 215]. Along with feature selection methods, these models combine different sMRI cortical and subcortical volumetric measures to identify disease subtypes [216]. Neural networks (NNs) based on sMRI and cognitive scores can predict the conversion of $\mathrm{MCI}$ to $\mathrm{AD}$
(cMCI) and distinguish between stable MCI and cMCI $[214,217,218]$. ML classifiers can also differentiate between clinical syndromes of frontotemporal dementia (FTD) [219]. Longitudinal studies using feature extraction-based learning techniques provide improved atrophy measures with significantly lower mean absolute error and volumetric markers such as the hippocampus, posterior cingulate cortex and middle temporal gyrus for evaluating disease progression in AD and MCI [190, 220, 221].

\section{Multimodal machine learning}

ML is an optimal approach to combine the findings of different imaging modalities. NNs based on grey matter density from MRI and glucose metabolism from PET yields better results than individual modalities [215, 222, 223]. Structural and connectivity measures from MRI combined with metabolism rate from PET predict the conversion of $\mathrm{MCI}$ to $\mathrm{AD}$. Deep learning models can predict $\mathrm{cMCI}$ from non-white matter extractions using PET images combined with MRI images. NNs based on sMRI or resting-state fMRI, cognitive and functional assessments show enhanced automatic diagnosis of both $\mathrm{AD}$ and MCI [224]. ML techniques can be used to combine clinical measures with multiple imaging modalities to understand the neuropathological processes of diseases [225].

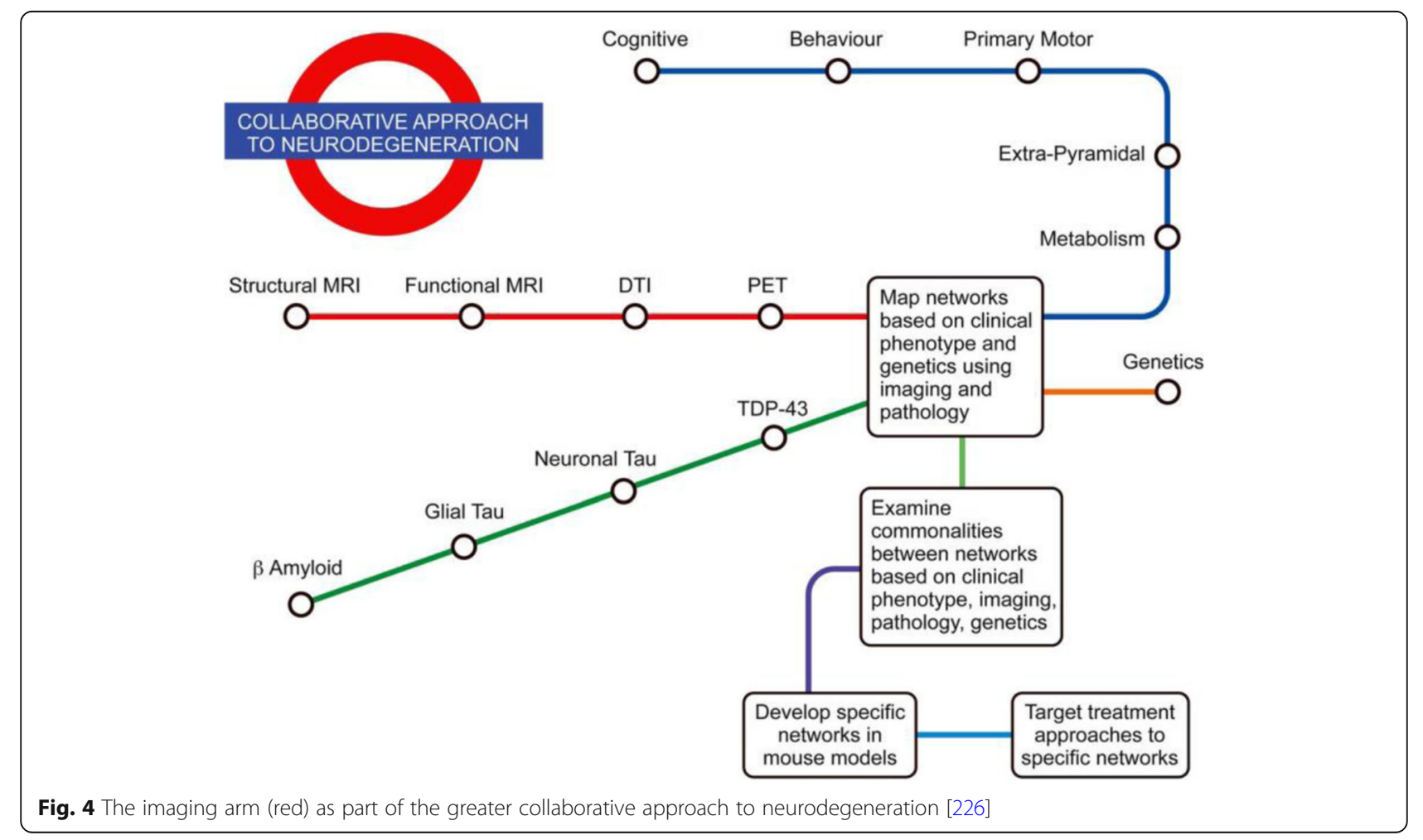




\section{Conclusion}

There is a growing body of evidence that imaging biomarkers can be useful in the detection and monitoring of neurodegenerative diseases. Due to the complexity of many of the diseases being studied as well as a variation in the results reported, extracting definitive findings remains a challenge. With ongoing and planned trials for various treatments, it is important to incorporate imaging biomarkers into these trials as well as continuing to improve the diagnostic and prognostic power of these techniques. On a wider scale, imaging biomarkers have a part to play in a collaborative approach to neurodegeneration (Fig. 4) as understanding and treatment becomes increasingly multidisciplinary.

\begin{abstract}
Abbreviations
1TC: 1 tissue compartment (model); AD: Alzheimer's disease; ASL: Arterial spin labelling; $A \beta$ : Amyloid-beta; $\mathrm{CMCl}$ : Converting mild cognitive impairment; CSF: Cerebrospinal fluid; CSVD: Cerebral small vessel disease; CT: Computed tomography; DLB: Dementia with Lewy bodies; DMN: Default mode network; DTI: Diffusion tensor imaging; FDG: 2-Fluoro-2-deoxy-Dglucose; fMRI: Functional magnetic resonance imaging; FTD: Frontotemporal dementia; KNN: k nearest neighbour; LSTMN: Long short-term memory network; MCl: Mild cognitive impairment; MRI: Magnetic resonance imaging; NFT: Neurofibrillary tangle; NN: Neural network; PD: Parkinson's disease; PET: Positron emission tomography; PHF: Paired helical filament; PiB: Pittsburgh compound B; QSM: Quantitative susceptibility mapping; RNN: Recurrent neural network; SMC: Subject memory complaints; sMRI: Structural magnetic resonance imaging; SRTM: Simplified reference tissue model; SUV: Standardised uptake value; SUVR: Standardised uptake value ratio; SV2A: Synaptic vesicle glycoprotein 2A; SVM: Support vector machines; WMH: White matter hypointensities
\end{abstract}

\section{Acknowledgements}

This research did not receive any specific grant from funding agencies in the public, commercial or not-for-profit sectors.

\section{Authors' contributions}

$P Y, M E, E C, M S, H B, M B, A M, A V, R L, D J, E M$ and $D B$ wrote the manuscript. $A O, N F, J P, W J, S C, R P$ and MS critically reviewed the manuscript. The authors read and approved the final manuscript.

\section{Authors' information}

This review article is part of a series of articles that has stemmed from the "Biomarkers in neurodegenerative disease" 2019 course run collaboratively between UCL and the University of Gothenburg. The attendees of this course have authored this article with the presenters of this course critically reviewing their work.

\section{Funding}

The UCL Biomedical Research Centre (BRC) provided funding for the "Biomarkers in neurodegenerative disease" course that this review is based on. Open access funding provided by the University of Gothenburg.

\section{Availability of data and materials}

This review does not contain any analysable data. All sources cited in this paper are publicly available.

\section{Ethics approval and consent to participate}

Not applicable.

\section{Consent for publication}

Not applicable.

\section{Competing interests}

The authors have no conflicts of interest to disclose.

\section{Author details}

'Wallenberg Centre for Molecular and Translational Medicine and the Department of Psychiatry and Neurochemistry, University of Gothenburg, Sahlgrenska University Hospital, Gothenburg, Sweden. ${ }^{2}$ Centre for Medical Image Computing (CMIC), Department of Computer Science \& Department of Medical Physics and Biomedical Engineering, University College London, London, UK. ${ }^{3}$ Department of Radiology and Nuclear Medicine, Amsterdam Neuroscience, Vrije Universiteit Amsterdam, Amsterdam UMC, Amsterdam, Netherlands. ${ }^{4}$ Neuroscience and Aphasia Research Unit, Division of Neuroscience and Experimental Psychology, The University of Manchester, Manchester, UK. ${ }^{5}$ German Center for Neurodegenerative Diseases (DZNE), Magdeburg, Germany. ${ }^{6}$ Division of Brain Sciences, Imperial College London, London, UK. ${ }^{7}$ United Kingdom Dementia Research Institute, Imperial College London, London, UK. ${ }^{8}$ Cardiff University Brain Research Imaging Centre (CUBRIC), School of Psychology, Cardiff, UK. 'Dementia Research Centre, UCL Institute of Neurology, University College London, London, UK. ${ }^{10}$ Department of Neurological Sciences, Faculty of Medicine, University of Chile, Santiago, Chile. ${ }^{11}$ Institute of Cognitive Neurology and Dementia Research, Otto-von-Guericke-University Magdeburg, Magdeburg, Germany. ${ }^{12}$ Trinity College Dublin, The University of Dublin, Dublin, Ireland. ${ }^{13}$ Clinical Memory Research Unit, Department of Clinical Sciences Malmö, Lund University, Lund, Sweden. ${ }^{14}$ Division of Clinical Geriatrics, Department of Neurobiology, Care Sciences and Society, Karolinska Institutet, Stockholm, Sweden. ${ }^{15}$ Helen Wills Neuroscience Institute, University of California, Berkeley, USA. ${ }^{16}$ Molecular Biophysics and Integrated Bioimaging, Lawrence Berkeley National Laboratory, Berkeley, CA, USA. ${ }^{17}$ Department of Psychiatry, School of Clinical Medicine, University of Cambridge, Cambridge, UK. ${ }^{18}$ Wolfson Molecular Imaging Centre, Division of Neuroscience and Experimental Psychology, MAHSC, University of Manchester, Manchester, UK. ${ }^{19}$ Department of Clinical Physiology, Sahlgrenska University Hospital, Gothenburg, Sweden.

Received: 24 October 2019 Accepted: 1 April 2020

Published online: 27 April 2020

\section{References}

1. Douaud G, Refsum H, de Jager CA, Jacoby RE, Nichols T, Smith SM, et al. Preventing Alzheimer's disease-related gray matter atrophy by B-vitamin treatment. Proc National Acad Sci. 2013;110(23):9523 Available from: http:// www.pnas.org/content/110/23/9523.abstract.

2. Jack CR, Holtzman DM. Biomarker modeling of Alzheimer's disease. Neuron. 2013;80(6):1347-58 [cited 2019 Aug 15] Available from: http://www.ncbi. nlm.nih.gov/pubmed/24360540.

3. Jack CR Jr, Bennett DA, Blennow K, Carrillo MC, Dunn B, Haeberlein SB, et al. NIA-AA Research Framework: toward a biological definition of Alzheimer's disease. Alzheimer's Dementia. 2018;14(4):535-62 Available from: https:// www.ncbi.nlm.nih.gov/pubmed/29653606.

4. Phelps ME, Huang SC, Hoffman EJ, Selin C, Sokoloff L, Kuhl DE. Tomographic measurement of local cerebral glucose metabolic rate in humans with ( $F$ 18)2-fluoro-2-deoxy-D-glucose: validation of method. Annals Neurol. 1979; 6(5):371-88 [cited 2019 Aug 15] Available from: http://www.ncbi.nlm.nih. gov/pubmed/117743.

5. Hoffman JM, Welsh-Bohmer KA, Hanson M, Crain B, Hulette C, Earl N, et al FDG PET imaging in patients with pathologically verified dementia. J Nuclear Medicine. 2000;41(11):1920-8 Available from: http://jnm. snmjournals.org/content/41/11/1920.abstract.

6. Rocher AB, Chapon F, Blaizot X, Baron J-C, Chavoix C. Resting-state brain glucose utilization as measured by PET is directly related to regional synaptophysin levels: a study in baboons. Neurolmage. 2003;20(3):1894-8 [cited 2019 Aug 15] Available from: http://www.ncbi.nlm.nih.gov/ pubmed/14642499.

7. Tada T, Hasegawa C, Odagawa T, Abe S, Kato K. Comparative examination of the cerebellum and pons as reference regions for quantitative evaluation in PET imaging for Alzheimer's disease using11C-Pittsburgh Compound-B. Journal of Nuclear Medicine. 2019;60(supplement 1):3012. Available from: http://jnm.snmjournals.org/content/60/supplement_1/3012.abstract.

8. Brown RKJ, Bohnen NI, Wong KK, Minoshima S, Frey KA. Brain PET in suspected dementia: patterns of altered FDG metabolism. Radiographics. 34(3):684-701 [cited 2019 Aug 15] Available from: http://www.ncbi.nlm.nih. gov/pubmed/24819789.

9. Herholz K, Haense C, Gerhard A, Jones M, Anton-Rodriguez J, Segobin S, et al. Metabolic regional and network changes in Alzheimer's disease subtypes. J 
Cerebral Blood Flow Metabolism. 2018;38(10):1796-806 [cited 2019 Aug 15]Available from: http://www.ncbi.nlm.nih.gov/pubmed/28675110.

10. Nestor PJ, Altomare D, Festari C, Drzezga A, Rivolta J, Walker Z, et al. Clinical utility of FDG-PET for the differential diagnosis among the main forms of dementia. Eur J Nuclear Med Mol Imaging. 2018:45(9):1509-25 Available from: https://doi.org/10.1007/s00259-018-4035-y.

11. Mosconi L, Berti V, Glodzik L, Pupi A, de Santi S, de Leon MJ. Pre-clinical detection of Alzheimer's disease using FDG-PET, with or without amyloid imaging. J Alzheimer's Disease. 2010;20:843-54.

12. Smailagic $N$, Vacante $M$, Hyde $C$, Martin S, Ukoumunne $O$, Sachpekidis $C$. 18F-FDG PET for the early diagnosis of Alzheimer's disease dementia and other dementias in people with mild cognitive impairment (MCI). Vol. 2017, Cochrane Database of Systematic Reviews. Wiley; 2015.

13. Anazodo UC, Finger E, Kwan BYM, Pavlosky W, Warrington JC, Günther M, et al. Using simultaneous PET/MRI to compare the accuracy of diagnosing frontotemporal dementia by arterial spin labelling MRI and FDG-PET. Neurolmage Clin. 2018;17:405-14 [cited 2019 Aug 15] Available from: http:// www.ncbi.nlm.nih.gov/pubmed/29159053.

14. Whitwell JL, Graff-Radford J, Singh TD, Drubach DA, Senjem ML, Spychalla AJ, et al. 18F-FDG PET in posterior cortical atrophy and dementia with Lewy bodies. J Nuclear Med. 2017;58(4):632-8 [cited 2019 Aug 15] Available from: http://www.ncbi.nlm.nih.gov/pubmed/27688479.

15. Sprinz C, Altmayer S, Zanon M, Watte G, Irion K, Marchiori E, et al. Effects of blood glucose level on 18F-FDG uptake for PET/CT in normal organs: a systematic review. PloS One. 2018;13(2):e0193140 Available from: https:// www.ncbinlm.nih.gov/pubmed/29486008.

16. Selkoe DJ, Hardy J. The amyloid hypothesis of Alzheimer's disease at 25 years. EMBO Mol Med. 2016;8(6):595-608 Available from: https://www.ncbi. nIm.nih.gov/pubmed/27025652.

17. Iwatsubo T, Odaka A, Suzuki N, Mizusawa H, Nukina N, Ihara Y. Visualization of $A \beta 42(43)$ and $A \beta 40$ in senile plaques with end-specific $A \beta$ monoclonals: evidence that an initially deposited species is Aß42(43). Neuron. 1994;13(1): 45-53 [cited 2019 Aug 15] Available from: https://www.sciencedirect.com/ science/article/pii/0896627394904588.

18. Krause DL, Müller N. Neuroinflammation, microglia and implications for anti-inflammatory treatment in Alzheimer's disease. Int J Alzheimer's Disease. 2010;2010:732806 Available from: https://www.ncbi.nlm.nih.gov/ pubmed/20798769.

19. Mokhtar SH, Bakhuraysah MM, Cram DS, Petratos S. The beta-amyloid protein of Alzheimer's disease: communication breakdown by modifying the neuronal cytoskeleton. Int J Alzheimer's Dis. 2013;2013:910502 Available from: https://www.ncbi.nlm.nih.gov/pubmed/24416616

20. Small GW, Kepe V, Ercoli LM, Siddarth P, Bookheimer SY, Miller KJ, et al. PET of brain amyloid and tau in mild cognitive impairment. New England J Med. 2006;355(25):2652-63 Available from: https://doi.org/10.1056/ NEJMoa054625.

21. Grothe MJ, Barthel H, Sepulcre J, Dyrba M, Sabri O, Teipel SJ, et al. In vivo staging of regional amyloid deposition. Neurology. 2017;89(20):2031-8 Available from: https://www.ncbi.nlm.nih.gov/pubmed/29046362.

22. Edmonds EC, Bangen KJ, Delano-Wood L, Nation DA, Furst AJ, Salmon DP, et al. Patterns of cortical and subcortical amyloid burden across stages of preclinical Alzheimer's disease. J Int Neuropsychol Soc. 2016;22(10):978-90 Available from: https://www.ncbi.nlm.nih.gov/pubmed/27903335.

23. Landau SM, Lu M, Joshi AD, Pontecorvo M, Mintun MA, Trojanowski JQ, et al. Comparing positron emission tomography imaging and cerebrospinal fluid measurements of $\beta$-amyloid. Ann Neurol 2013;74(6):826-36. Available from: https://www.ncbi.nlm.nih.gov/pubmed/23536396.

24. Ikonomovic MD, Klunk WE, Abrahamson EE, Mathis CA, Price JC, Tsopelas ND, et al. Post-mortem correlates of in vivo PiB-PET amyloid imaging in a typical case of Alzheimer's disease. Brain. 2008/03/12. 2008 131(Pt 6):1630-45. Available from: https://www.ncbi.nlm.nih.gov/ pubmed/18339640.

25. Klunk WE, Engler $\mathrm{H}$, Nordberg A, Wang $Y$, Blomqvist $G$, Holt DP, et al. Imaging brain amyloid in Alzheimer's disease with Pittsburgh Compound-B. Ann Neurol. 2004:55(3):306-19. Available from: https://doi. org/10.1002/ana.20009.

26. Nelissen N, van Laere K, Thurfjell L, Owenius R, Vandenbulcke M, Koole M, et al. Phase 1 study of the Pittsburgh compound B derivative 18Fflutemetamol in healthy volunteers and patients with probable Alzheimer disease. J Nuclear Med. 2009;50(8):1251-9 Available from: http://jnm. snmjournals.org/content/50/8/1251.abstract.
27. Wolk DA, Zhang Z, Boudhar S, Clark CM, Pontecorvo MJ, Arnold SE. Amyloid imaging in Alzheimer's disease: comparison of florbetapir and Pittsburgh compound-B positron emission tomography. Journal of neurology, neurosurgery, and psychiatry. 2012/07/11. 2012;83(9):923-6. Available from: https://www.ncbi.nlm.nih.gov/pubmed/22791901.

28. Choi SR, Golding G, Zhuang Z, Zhang W, Lim N, Hefti F, et al. Preclinical properties of 18F-AV-45: a PET agent for Abeta plaques in the brain. Journal of nuclear medicine : official publication, Society of Nuclear Medicine. 2009/ 10/16. 2009;50(11):1887-94. Available from: https://www.ncbi.nlm.nih.gov/ pubmed/19837759.

29. Ikonomovic MD, Buckley CJ, Heurling K, Sherwin P, Jones PA, Zanette M, et al. Post-mortem histopathology underlying $\beta$-amyloid PET imaging following flutemetamol F 18 injection. Acta Neuropathologica Communications. 2016;4(1):130. Available from: https://doi.org/10.1186/ s40478-016-0399-z.

30. Rowe CC, Pejoska S, Mulligan RS, Jones G, Chan JG, Svensson S, et al. Headto-head comparison of 11C-PiB and 18F-AZD4694 (NAV4694) for B-amyloid imaging in aging and dementia. J Nuclear Med. 2013;54(6):880-6 Available from: http://jnm.snmjournals.org/content/54/6/880.abstract.

31. Bullich S, Villemagne VL, Catafau AM, Jovalekic A, Koglin N, Rowe CC, et al. Optimal reference region to measure longitudinal amyloid- $\beta$ change with 18F-Florbetaben PET. J Nuclear Medicine. 2017;58(8):1300-6 Available from: http://jnm.snmjournals.org/content/58/8/1300.abstract.

32. Chiao P, Bedell BJ, Avants B, Zijdenbos AP, Grand'Maison M, O'Neill P, et al. Impact of reference and target region selection on amyloid PET SUV ratios in the phase 1b PRIME study of aducanumab. J Nuclear Medicine. 2019;60(1): 100-6 Available from: http://jnm.snmjournals.org/content/60/1/100.abstract.

33. Jack CR, Wiste HJ, Weigand SD, Therneau TM, Lowe VJ, Knopman DS, et al. Defining imaging biomarker cut points for brain aging and Alzheimer's disease. Alzheimer's \& Dementia. 2017;13(3):205-16 Available from: http:// www.sciencedirect.com/science/article/pii/S1552526016328758.

34. Klunk WE, Koeppe RA, Price JC, Benzinger TL, Devous Sr MD, Jagust WJ, et al. The Centiloid Project: standardizing quantitative amyloid plaque estimation by PET. Alzheimer's \& dementia : the journal of the Alzheimer's association. 2014/10/28. 2015 Jan;11(1):1-15.e154. Available from: https:// www.ncbi.nlm.nih.gov/pubmed/25443857.

35. Salvadó G, Molinuevo JL, Brugulat-Serrat A, Falcon C, Grau-Rivera O, SuárezCalvet $\mathrm{M}$, et al. Centiloid cut-off values for optimal agreement between PET and CSF core AD biomarkers. Alzheimer's Research \& Therapy. 2019;1 1(1):27. Available from: https://doi.org/10.1186/s13195-019-0478-z.

36. Su Y, Flores S, Hornbeck RC, Speidel B, Vlassenko AG, Gordon BA, et al. Utilizing the Centiloid scale in cross-sectional and longitudinal PiB PET studies. Neurolmage Clinical. 2018 ;19:406-16. Available from: https://www. ncbi.nlm.nih.gov/pubmed/30035025.

37. Battle MR, Pillay LC, Lowe VJ, Knopman D, Kemp B, Rowe CC, et al. Centiloid scaling for quantification of brain amyloid with [(18)F]flutemetamol using multiple processing methods. EJNMMI research. 2018;8(1):107. Available from: https://www.ncbi.nlm.nih.gov/pubmed/30519791.

38. Yamao T, Miwa K, Matsuda H, Akamatsu G, Wagatsuma K, Takano H. Feasibility of 18F-THK5351 PET quantitation using the Centiloid scale. Journal of Nuclear Medicine. 2019;60(supplement 1):1182. Available from: http://jnm.snmjournals.org/content/60/supplement_1/1182.abstract.

39. Dubois B, Feldman HH, Jacova C, Cummings JL, DeKosky ST, Barberger-Gateau P, et al. Revising the definition of Alzheimer's disease: a new lexicon. The Lancet Neurology. 2010 [cited 2019 Aug 15];9(11):1118-27. Available from: https:/www. sciencedirect.com/science/article/pii/S1474442210702234?via\%3Dihub.

40. Vandenberghe R, Adamczuk K, Dupont P, Laere K van, Chételat G. Amyloid PET in clinical practice: its place in the multidimensional space of Alzheimer's disease. Neurolmage Clinical. 2013;2:497-511. Available from: https://www.ncbi.n/m.nih.gov/pubmed/24179802.

41. Ketter N, Brashear HR, Bogert J, Di J, Miaux Y, Gass A, et al. Central review of amyloid-related imaging abnormalities in two phase III clinical trials of bapineuzumab in mild-to-moderate Alzheimer's disease patients. Journal of Alzheimer's disease : JAD. 2017 [cited 2019 Aug 15]; 57(2):557-73. Available from: http://www.ncbi.nlm.nih.gov/pubmed/2826 9765.

42. Toyn $J$, Ahlijanian MK. Interpreting Alzheimer's disease clinical trials in light of the effects on amyloid- $\beta$. Alzheimer's Research \& Therapy. 2014;6(2):14. Available from: https://doi.org/10.1186/alzrt244.

43. Johnson KA, Schultz A, Betensky RA, Becker JA, Sepulcre J, Rentz D, et al. Tau positron emission tomographic imaging in aging and early Alzheimer 
disease. Annals of Neurology. 2016;79(1):110-9. Available from: https://doi. org/10.1002/ana.24546.

44. Goedert M, Spillantini MG, Jakes R, Rutherford D, Crowther RA. Multiple isoforms of human microtubule-associated protein tau: sequences and localization in neurofibrillary tangles of Alzheimer's disease. Neuron. 1989 [cited 2019 Aug 15];3(4):519-26. Available from: https://www.sciencedirect. com/science/article/pii/0896627389902109?via\%3Dihub.

45. Buée L, Bussière T, Buée-Scherrer V, Delacourte A, Hof PR. Tau protein isoforms, phosphorylation and role in neurodegenerative disorders. Brain research Brain research reviews. 2000 [cited 2019 Aug 15];33(1):95-130. Available from: http://www.ncbi.n/m.nih.gov/pubmed/10967355.

46. Marquié M, Normandin MD, Vanderburg CR, Costantino IM, Bien EA, Rycyna LG, et al. Validating novel tau positron emission tomography tracer [F-18]AV-1451 (T807) on postmortem brain tissue. Ann Neurol. 2015 1;78(5):787800. Available from: https://doi.org/10.1002/ana.24517.

47. Marquié M, Normandin MD, Meltzer AC, Siao Tick Chong M, Andrea N V, Antón-Fernández A, et al. Pathological correlations of [F-18]-AV-1451 imaging in non-alzheimer tauopathies. Annals of Neurology. 2017;81(1):11728. Available from: https://doi.org/10.1002/ana.24844.

48. Lowe VJ, Lundt ES, Albertson SM, Min H-K, Fang P, Przybelski SA, et al. Taupositron emission tomography correlates with neuropathology findings. Alzheimer'sDementia. 2019; Available from: http://www.sciencedirect.com/ science/article/pii/S1552526019354755.

49. Smith R, Puschmann A, Schöll M, Ohlsson T, van Swieten J, Honer M, et al. 18F-AV-1451 tau PET imaging correlates strongly with tau neuropathology in MAPT mutation carriers. Brain. 2016;139(9):2372-9. Available from: https:// doi.org/10.1093/brain/aww163.

50. Smith R, Wibom M, Pawlik D, Englund E, Hansson O. Correlation of in vivo [18F]Flortaucipir with postmortem Alzheimer disease tau pathology. JAMA Neurology. 2019;76(3):310-7. Available from: https://doi.org/10.1001/ jamaneurol.2018.3692.

51. Okamura N, Furumoto S, Harada R, Tago T, Yoshikawa T, Fodero-Tavoletti M, et al. Novel 18F-labeled arylquinoline derivatives for noninvasive imaging of Tau pathology in Alzheimer disease. J Nucl Med. 2013;54(8):1420-7.

52. Maruyama M, Shimada H, Suhara T, Shinotoh H, Ji B, Maeda J, et al. Imaging of tau pathology in a tauopathy mouse model and in Alzheimer patients compared to normal controls. Neuron. 2013 [cited 2019 Aug 15];79(6):1094108. Available from: http://www.ncbi.nlm.nih.gov/pubmed/24050400.

53. Chien DT, Bahri S, Szardenings AK, Walsh JC, Mu F, Su M-Y, et al. Early clinical PET imaging results with the novel PHF-tau radioligand [F-18]-T807. J Alzheimer's Dis. 2013 [cited 2019 Aug 15];34(2):457-68. Available from: http://www.ncbi.nlm.nih.gov/pubmed/23234879.

54. Gobbi LC, Knust H, Körner M, Honer M, Czech C, Belli S, et al. Identification of three novel radiotracers for imaging aggregated tau in Alzheimer's disease with positron emission tomography. J Medicinal Chem. 2017 ;60(17): 7350-70. Available from: https://doi.org/10.1021/acs.jmedchem.7b00632.

55. Walji AM, Hostetler ED, Selnick H, Zeng Z, Miller P, Bennacef I, et al. Discovery of 6-(Fluoro-(18)F)-3-(1H-pyrrolo[2,3-c]pyridin-1-yl)isoquinolin-5amine ([(18)F]-MK-6240): a positron emission tomography (PET) imaging agent for quantification of neurofibrillary tangles (NFTs). Journal of medicinal chemistry. 2016 [cited 2019 Aug 15];59(10):4778-89. Available from: http://www.ncbi.nlm.nih.gov/pubmed/27088900.

56. Aguero C, Dhaynaut M, Normandin MD, Amaral AC, Guehl NJ, Neelamegam $\mathrm{R}$, et al. Autoradiography validation of novel tau PET tracer [F-18]-MK-6240 on human postmortem brain tissue. Acta Neuropathologica Communications. 2019;7(1):37. Available from: https://doi.org/10.1186/ s40478-019-0686-6.

57. Okamura N, Harada R, Ishiki A, Kikuchi A, Nakamura T, Kudo Y. The development and validation of tau PET tracers: current status and future directions. Clinical and Translational Imaging. 2018/07/20. 2018; 6(4):305-16. Available from: https://www.ncbi.nlm.nih.gov/pubmed/3 0148121.

58. Sanabria Bohórquez S, Marik J, Ogasawara A, Tinianow JN, Gill HS, Barret O, et al. [18F]GTP1 (Genentech Tau Probe 1), a radioligand for detecting neurofibrillary tangle tau pathology in Alzheimer's disease. European journal of Nuclear Medicine and Molecular Imaging. 2019;46(10):2077-89. Available from: https://doi.org/10.1007/s00259-019-04399-0.

59. Fawaz M v, Brooks AF, Rodnick ME, Carpenter GM, Shao X, Desmond TJ, et al. High affinity radiopharmaceuticals based upon lansoprazole for PET imaging of aggregated tau in Alzheimer's disease and progressive supranuclear palsy: synthesis, preclinical evaluation, and lead selection. ACS chemical neuroscience. 2014/06/16. 2014;5(8):718-30. Available from: https://www.ncbi.nlm.nih.gov/pubmed/24896980.

60. Walji AM, Hostetler ED, Selnick $H$, Zeng Z, Miller P, Bennacef I, et al. Discovery of 6-(Fluoro-18F)-3-(1H-pyrrolo[2,3-c]pyridin-1-yl)isoquinolin-5amine ([18F]-MK-6240): a positron emission tomography (PET) imaging agent for quantification of neurofibrillary tangles (NFTs). Journal of Medicinal Chemistry. 2016;59(10):4778-89. Available from: https://doi.org/10. 1021/acs.jmedchem.6b00166.

61. Hostetler ED, Walji AM, Zeng Z, Miller P, Bennacef I, Salinas C, et al. Preclinical characterization of 18F-MK-6240, a promising PET tracer for in vivo quantification of human neurofibrillary tangles. Journal of Nuclear Medicine. 2016;57(10):1599-606 Available from: http://jnm.snmjournals.org/ content/57/10/1599.abstract.

62. Wong DF, Comley R, Kuwabara H, Rosenberg PB, Resnick SM, Ostrowitzki S, et al. First in-human PET study of 3 novel tau radiopharmaceuticals: [11C]RO6924963, [11C]RO6931643, and [18F]RO6958948. Journal of Nuclear Medicine. 2018; Available from: http://jnm.snmjournals.org/content/early/2 018/05/03/jnumed.118.209916.abstract.

63. Schöll M, Lockhart SN, Schonhaut DR, O'Neil JP, Janabi M, Ossenkoppele R, et al. PET imaging of tau deposition in the aging human brain. Neuron. 2016 [cited 2019 Aug 15];89(5):971-82. Available from: http://www.ncbi.nIm. nih.gov/pubmed/26938442.

64. Braak H, Braak E. Neuropathological stageing of Alzheimer-related changes. Acta Neuropathologica. 1991;82(4):239-59. Available from: https://doi.org/10 1007/BF00308809.

65. Cho H, Choi JY, Hwang MS, Kim YJ, Lee HM, Lee HS, et al. In vivo cortical spreading pattern of tau and amyloid in the Alzheimer disease spectrum. Annals of neurology. 2016 [cited 2019 Aug 15];80(2):247-58. Available from: http://www.ncbi.nlm.nih.gov/pubmed/27323247.

66. Ossenkoppele R, Schonhaut DR, Schöll M, Lockhart SN, Ayakta N, Baker SL, et al. Tau PET patterns mirror clinical and neuroanatomical variability in Alzheimer's disease. Brain. 2016 [cited 2019 Aug 15]; 139(Pt 5):1551-67. Available from: http://www.ncbi.nlm.nih.gov/ pubmed/26962052.

67. Xia C, Makaretz SJ, Caso C, McGinnis S, Gomperts SN, Sepulcre J, et al. Association of in vivo [18F]AV-1451 tau PET imaging results with cortical atrophy and symptoms in typical and atypical Alzheimer disease. JAMA neurology. 2017 [cited 2019 Aug 15];74(4):427-36. Available from: http:// www.ncbi.nlm.nih.gov/pubmed/28241163.

68. Crary JF, Trojanowski JQ, Schneider JA, Abisambra JF, Abner EL, Alafuzoff I, et al. Primary age-related tauopathy (PART): a common pathology associated with human aging. Acta neuropathologica. 2014 [cited 2019 Aug 15];128(6):755-66. Available from: http://www.ncbi.nlm.nih.gov/ pubmed/25348064.

69. Josephs KA, Murray ME, Tosakulwong N, Whitwell JL, Knopman DS, Machulda MM, et al. Tau aggregation influences cognition and hippocampal atrophy in the absence of beta-amyloid: a clinico-imagingpathological study of primary age-related tauopathy (PART). Acta neuropathologica. 2017 [cited 2019 Aug 15];133(5):705-15. Available from: http://www.ncbi.nlm.nih.gov/pubmed/28160067.

70. Adams JN, Lockhart SN, Li L, Jagust WJ. Relationships between tau and glucose metabolism reflect Alzheimer's disease pathology in cognitively normal older adults. Cerebral cortex (New York, NY : 1991). 2019 [cited 2019 Aug 15];29(5):1997-2009. Available from: http://www.ncbi.nlm.nih.gov/ pubmed/29912295.

71. Maass A, Lockhart SN, Harrison TM, Bell RK, Mellinger T, Swinnerton K, et al. Entorhinal tau pathology, episodic memory decline, and neurodegeneration in aging. J Neurosci. 2018 [cited 2019 Aug 15];38(3):530-43. Available from: http://www.ncbi.nlm.nih.gov/pubmed/29192126.

72. Hanseeuw BJ, Betensky RA, Schultz AP, Papp K v, Mormino EC, Sepulcre J, et al. Fluorodeoxyglucose metabolism associated with tau-amyloid interaction predicts memory decline. Annals Neurol. 2017 [cited 2019 Aug 15];81(4):583-96. Available from: http://www.ncbi.nlm.nih.gov/pubmed/2 8253546

73. Ossenkoppele R, Smith R, Ohlsson T, Strandberg O, Mattsson N, Insel PS, et al. Associations between tau, $A \beta$, and cortical thickness with cognition in Alzheimer disease. Neurology. 2019;92(6):e601. Available from: http://n. neurology.org/content/92/6/e601.abstract.

74. Pontecorvo MJ, Devous MD, Kennedy I, Navitsky M, Lu M, Galante N, et al. A multicentre longitudinal study of flortaucipir (18F) in normal ageing, mild cognitive impairment and Alzheimer's disease dementia. Brain. 2019 [cited 
2019 Aug 15];142(6):1723-35. Available from: http://www.ncbi.nlm.nih.gov/ pubmed/31009046.

75. Ossenkoppele R, Rabinovici GD, Smith R, Cho H, Schöll M, Strandberg O, et al. Discriminative accuracy of [18F]flortaucipir positron emission tomography for Alzheimer disease vs other neurodegenerative disorders. JAMA. 2018 [cited 2019 Aug 15];320(11):1151-62. Available from: http:// www.ncbi.nlm.nih.gov/pubmed/30326496.

76. Mattsson N, Smith R, Strandberg O, Palmqvist S, Schöll M, Insel PS, et al. Comparing (18)F-AV-1451 with CSF t-tau and p-tau for diagnosis of Alzheimer disease. Neurology. 2018/01/10. 2018;90(5):e388-95. Available from: https://www.ncbi.nlm.nih.gov/pubmed/29321235.

77. Wang L, Benzinger TL, Su Y, Christensen J, Friedrichsen K, Aldea P, et al. Evaluation of tau imaging in staging Alzheimer disease and revealing interactions between $\beta$-amyloid and tauopathy. JAMA neurology. 2016 [cited 2019 Aug 15];73(9):1070-7. Available from: http://www.ncbi.nlm.nih. gov/pubmed/27454922.

78. Pontecorvo MJ, Devous Sr MD, Navitsky M, Lu M, Salloway S, Schaerf FW, et al. Relationships between flortaucipir PET tau binding and amyloid burden, clinical diagnosis, age and cognition. Brain. 2017;140(3):748-63. Available from: https:/www.ncbi.nlm.nih.gov/pubmed/28077397.

79. Villemagne VL, Doré V, Burnham SC, Masters CL, Rowe CC. Imaging tau and amyloid- $\beta$ proteinopathies in Alzheimer disease and other conditions. Nature reviews Neurology. 2018 [cited 2019 Aug 15];14(4):225-36. Available from: http://www.ncbi.nlm.nih.gov/pubmed/29449700.

80. Jacobs HIL, Hedden T, Schultz AP, Sepulcre J, Perea RD, Amariglio RE, et al. Structural tract alterations predict downstream tau accumulation in amyloid-positive older individuals. Nature Neuroscience. 2018/02/05. 2018;21(3):424-31. Available from: https://www.ncbi.nlm.nih.gov/ pubmed/29403032.

81. Südhof TC. Neuroligins and neurexins link synaptic function to cognitive disease. Nature. 2008;455:903. Available from: https://doi.org/10.1038/ nature 07456.

82. Terry RD, Masliah E, Salmon DP, Butters N, DeTeresa R, Hill R, et al. Physical basis of cognitive alterations in Alzheimer's disease: synapse loss is the major correlate of cognitive impairment. Ann Neurol. 1991 [cited 2019 Aug 15];30(4):572-80. Available from: http://www.ncbi.nlm. nih.gov/pubmed/1789684.

83. Robinson JL, Molina-Porcel L, Corrada MM, Raible K, Lee EB, Lee VM-Y, et al. Perforant path synaptic loss correlates with cognitive impairment and Alzheimer's disease in the oldest-old. Brain. 2014/07/09. 2014;137(Pt 9): 2578-87. Available from: https://www.ncbi.nlm.nih.gov/pubmed/25012223.

84. Finnema SJ, Nabulsi NB, Eid T, Detyniecki K, Lin S, Chen M-K, et al. Imaging synaptic density in the living human brain. Sci Transl Med. 2016;8(348):348ra96. Available from: http://stm.sciencemag.org/content/ 8/348/348ra96.abstract.

85. Rabiner EA. Imaging synaptic density: a different look at neurologic diseases. J Nuclear Med. 2018;59(3):380-1 Available from: http://jnm. snmjournals.org/content/59/3/380.short.

86. Vogl C, Tanifuji S, Danis B, Daniels V, Foerch P, Wolff C, et al. Synaptic vesicle glycoprotein $2 \mathrm{~A}$ modulates vesicular release and calcium channel function at peripheral sympathetic synapses. Eur J Neurosci. 2015;41(4):398-409. Available from: https://doi.org/10.1111/ejn.12799.

87. Bajjalieh SM, Frantz GD, Weimann JM, McConnell SK, Scheller RH. Differential expression of synaptic vesicle protein 2 (SV2) isoforms. J Neurosci. 1994;14(9):5223. Available from: http://www.jneurosci.org/ content/14/9/5223.abstract.

88. Nabulsi NB, Mercier J, Holden D, Carré S, Najafzadeh S, Vandergeten M-C, et al. Synthesis and preclinical evaluation of 11C-UCB-J as a PET tracer for imaging the synaptic vesicle glycoprotein $2 \mathrm{~A}$ in the brain. J Nuclear Medicine. 2016;57(5):777-84 Available from: http://jnm.snmjournals.org/ content/57/5/777.abstract.

89. Finnema SJ, Nabulsi NB, Mercier J, Lin S-F, Chen M-K, Matuskey D, et al. Kinetic evaluation and test-retest reproducibility of [11C]UCB-J, a novel radioligand for positron emission tomography imaging of synaptic vesicle glycoprotein 2A in humans. Journal of cerebral blood flow and metabolism : official journal of the International Society of Cerebral Blood Flow and Metabolism. 2018 [cited 2019 Aug 15];38(11):2041-52. Available from: http:// www.ncbi.nlm.nih.gov/pubmed/28792356.

90. Zheng M-Q, Holden D, Nabulsi N, Lin S, Mercier J, Hannestad J, et al. Synthesis and evaluation of 18F-UCB-H, a novel PET imaging tracer for the synaptic vesicle protein 2A.J Nuclear Medicine. 2014;55(supplement
1):1792. Available from: http://jnm.snmjournals.org/content/55/ supplement_1/1792.abstract.

91. Bretin F, Bahri MA, Bernard C, Warnock G, Aerts J, Mestdagh N, et al. Biodistribution and radiation dosimetry for the novel SV2A radiotracer [18F]UCB-H: first-in-human study. Molecular Imaging Biol. 2015;17(4):557-64. Available from: https://doi.org/10.1007/s11307-014-0820-6.

92. Bastin C, Bahri MA, Meyer F, Manard M, Delhaye E, Plenevaux A, et al. In vivo imaging of synaptic loss in Alzheimer's disease with [18F]UCB-H positron emission tomography. Eur I Nuclear Med Molecular Imaging. 2020; 47(2):390-402. Available from: https://doi.org/10.1007/s00259-019-04461-x.

93. laccarino L, Sala A, Caminiti SP, Perani D. The emerging role of PET imaging in dementia. F1000Research. 2017;6:1830. Available from: https://www.ncbi. nlm.nih.gov/pubmed/29071066.

94. Minoshima S, Drzezga AE, Barthel H, Bohnen N, Djekidel M, Lewis DH, et al. SNMMI procedure standard/EANM practice guideline for amyloid PET imaging of the brain 1.0. Journal of Nuclear Medicine. 2016;57(8):1316-22. Available from: http://jnm.snmjournals.org/content/57/8/1316.short.

95. Suppiah S, Didier M-A, Vinjamuri S. The who, when, why, and how of PET amyloid imaging in management of Alzheimer's disease-review of literature and interesting images. Diagnostics (Basel, Switzerland). 2019;9(2):65. Available from: https://www.ncbi.n/m.nih.gov/pubmed/31242587.

96. Wang YT, Edison P. Tau imaging in neurodegenerative diseases using positron emission tomography. Current neurology and neuroscience reports. 2019;19(7):45. Available from: https://www.ncbi.nlm.nih.gov/ pubmed/31172290.

97. Schöll M, Maass A, Mattsson N, Ashton NJ, Blennow K, Zetterberg H, et al. Biomarkers for tau pathology. Molecular and Cellular Neuroscience. 2019;97: 18-33 Available from: http://www.sciencedirect.com/science/article/pii/S1 044743118302331.

98. Leuzy A, Chiotis K, Lemoine L, Gillberg P-G, Almkvist O, Rodriguez-Vieitez E, et al. Tau PET imaging in neurodegenerative tauopathies-still a challenge. Molecular psychiatry. 2019;24(8):1112-34. Available from: https://doi.org/10. 1038/s41380-018-0342-8.

99. Klunk WE. Molecular imaging: what is right and what is an illusion? Alzheimer's \& Dementia: Diagnosis, Assessment \& Disease Monitoring. 2018; 10:217-20 Available from: http://www.sciencedirect.com/science/article/pii/ S2352872918300046

100. Rossano S, Toyonaga T, Finnema SJ, Naganawa M, Lu Y, Nabulsi N, et al. Assessment of a white matter reference region for 11C-UCB-J PET quantification. Journal of Cerebral Blood Flow \& Metabolism. 2019; 0271678X19879230. Available from: https://doi.org/10.1177/ $0271678 \times 19879230$.

101. (No Title). Dementia: assessment, management and support for people living with dementia and their carers. 2018 [Cited 2019 Aug 21]. Available from: http://www.ncbi.nlm.nih.gov/pubmed/30011160.

102. Frisoni GB, Pievani M, Testa C, Sabattoli F, Bresciani L, Bonetti M, et al. The topography of grey matter involvement in early and late onset Alzheimer's disease. Brain. 2007;130(3):720-30. Available from: https://doi.org/10.1093/ brain/awl377.

103. Möller C, Vrenken H, Jiskoot L, Versteeg A, Barkhof F, Scheltens $P$, et al. Different patterns of gray matter atrophy in early- and late-onset Alzheimer's disease. Neurobiology of Aging. 2013 [cited 2019 Aug 21];34(8): 2014-22. Available from: https://www.sciencedirect.com/science/article/pii/ S0197458013000869?via\%3Dihub.

104. Whitwell JL, Josephs KA, Murray ME, Kantarci K, Przybelski SA, Weigand SD, et al. MRI correlates of neurofibrillary tangle pathology at autopsy: a voxelbased morphometry study. Neurology. 2008;71(10):743-9. Available from: https://www.ncbi.nlm.nih.gov/pubmed/18765650.

105. Rohrer JD, Nicholas JM, Cash DM, van Swieten J, Dopper E, Jiskoot L, et al. Presymptomatic cognitive and neuroanatomical changes in genetic frontotemporal dementia in the Genetic Frontotemporal dementia Initiative (GENFI) study: a cross-sectional analysis. The Lancet Neurology. 2015 [cited 2019 Aug 21];14(3):253-62. Available from: https://www.sciencedirect.com/ science/article/pii/S1474442214703242?via\%3Dihub.

106. Mahoney CJ, Downey LE, Ridgway GR, Beck J, Clegg S, Blair M, et al. Longitudinal neuroimaging and neuropsychological profiles of frontotemporal dementia with C9ORF72 expansions. Alzheimer's research \& therapy. 2012;4(5):41. Available from: https://www.ncbi.nlm.nih.gov/ pubmed/23006986.

107. Román GC, Tatemichi TK, Erkinjuntti T, Cummings JL, Masdeu JC, Garcia JH, et al. Vascular dementia: diagnostic criteria for research studies. Report of 
the NINDS-AIREN International Workshop. Neurology. 1993 [cited 2019 Aug 22];43(2):250-60. Available from: http://www.ncbi.nlm.nih.gov/ pubmed/8094895.

108. Haller S, Vernooij MW, Kuijer JPA, Larsson E-M, Jäger HR, Barkhof F. Cerebral microbleeds: imaging and clinical significance. Radiology. 2018;287(1):11-28. Available from: https://doi.org/10.1148/radiol.2018170803.

109. Kallenberg K, Schulz-Schaeffer WJ, Jastrow U, Poser S, Meissner B, Tschampa $\mathrm{HJ}$, et al. Creutzfeldt-Jakob disease: comparative analysis of MR imaging sequences. Am J Neuroradiology. 2006;27(7):1459. Available from: http:// www.ajnr.org/content/27/7/1459.abstract.

110. McKhann GM, Knopman DS, Chertkow H, Hyman BT, Jack Jr CR, Kawas CH, et al. The diagnosis of dementia due to Alzheimer's disease: recommendations from the National Institute on Aging-Alzheimer's Association workgroups on diagnostic guidelines for Alzheimer's disease. Alzheimer's \& Dementia 2011/04/21. 2011;7(3):263-9. Available from: https:// www.ncbi.nlm.nih.gov/pubmed/21514250

111. Crutch SJ, Schott JM, Rabinovici GD, Murray M, Snowden JS, van der Flier WM, et al. Consensus classification of posterior cortical atrophy. Alzheimer's \& Dementia. 2017/03/02. 2017;13(8):870-84. Available from: https://www. ncbi.nlm.nih.gov/pubmed/28259709.

112. Gorno-Tempini ML, Hillis AE, Weintraub S, Kertesz A, Mendez M, Cappa SF, et al. Classification of primary progressive aphasia and its variants. Neurology. 2011/02/16. 2011;76(11):1006-14. Available from: https://www. ncbi.nlm.nih.gov/pubmed/21325651.

113. Rascovsky K, Hodges JR, Knopman D, Mendez MF, Kramer JH, Neuhaus J, et al. Sensitivity of revised diagnostic criteria for the behavioural variant of frontotemporal dementia. Brain : a journal of neurology. 2011/08/02. 2011 Sep;134(Pt 9):2456-77. Available from: https:/uww.ncbi.nlm.nih.gov/pubmed/21810890

114. McKeith IG, Boeve BF, Dickson DW, Halliday G, Taylor J-P, Weintraub D, et al. Diagnosis and management of dementia with Lewy bodies: fourth consensus report of the DLB Consortium. Neurology. 2017/06/07. 2017;89(1): 88-100. Available from: https://www.ncbinlm.nih.gov/pubmed/28592453.

115. Gilman S, Wenning GK, Low PA, Brooks DJ, Mathias CJ, Trojanowski JQ, et al. Second consensus statement on the diagnosis of multiple system atrophy. Neurology. 2008;71(9):670-6. Available from: https://www.ncbi.nlm.nih.gov/ pubmed/18725592.

116. Höglinger GU, Respondek G, Stamelou M, Kurz C, Josephs KA, Lang AE, et al. Clinical diagnosis of progressive supranuclear palsy: the movement disorder society criteria. Movement disorders : official journal of the Movement Disorder Society. 2017/05/03. 2017 Jun;32(6):853-64. Available from: https://www.ncbi.nlm.nih.gov/pubmed/28467028.

117. Harper L, Bouwman F, Burton EJ, Barkhof F, Scheltens P, O'Brien JT, et al. Patterns of atrophy in pathologically confirmed dementias: a voxelwise analysis. Journal of Neurology, Neurosurgery \&amp;amp; Psychiatry. 2017; 88(11):908. Available from: http://jnnp.bmj.com/content/88/11/908.abstract.

118. Jack Jr CR, Dickson DW, Parisi JE, Xu YC, Cha RH, O'Brien PC, et al. Antemortem MRI findings correlate with hippocampal neuropathology in typical aging and dementia. Neurology. 2002;58(5):750-7. Available from: https://www.ncbi.nlm.nih.gov/pubmed/11889239.

119. Boon BDC, Pouwels PJW, Jonkman LE, Keijzer MJ, Preziosa P, van de Berg WDJ, et al. Can post-mortem MRI be used as a proxy for in vivo? A case study. Brain Communications. 2019;1(1). Available from: https://doi.org/10. 1093/braincomms/fcz030.

120. Jack Jr CR, Knopman DS, Jagust WJ, Petersen RC, Weiner MW, Aisen PS, et al. Tracking pathophysiological processes in Alzheimer's disease: an updated hypothetical model of dynamic biomarkers. The Lancet Neurology. 2013;12(2):207-16. Available from: https://www.ncbi.nlm.nih.gov/ pubmed/23332364.

121. Ridha BH, Barnes J, Bartlett JW, Godbolt A, Pepple T, Rossor MN, et al, Tracking atrophy progression in familial Alzheimer's disease: a serial MRI study. The Lancet Neurology. 2006 [cited 2019 Aug 21];5(10):828-34. Available from: https://www.sciencedirect.com/science/article/pii/S14744422 06705506?via\%3Dihub.

122. Hill DLG, Schwarz AJ, Isaac M, Pani L, Vamvakas S, Hemmings R, et al. Coalition Against Major Diseases/European Medicines Agency biomarker qualification of hippocampal volume for enrichment of clinical trials in predementia stages of Alzheimer's disease. Alzheimer's \& Dementia. 2014 Jul 1 [cited 2019 Aug 21];10(4):421-429.e3. Available from: https://www. sciencedirect.com/science/article/pii/S1552526013024977?via\%3Dihub.

123. Fox NC, Cousens S, Scahill R, Harvey RJ, Rossor MN. Using serial registered brain magnetic resonance imaging to measure disease progression in
Alzheimer disease: power calculations and estimates of sample size to detect treatment effects. JAMA Neurology. 2000;57(3):339-44. Available from: https://doi.org/10.1001/archneur.57.3.339.

124. Kulason S, Tward DJ, Brown T, Sicat CS, Liu C-F, Ratnanather JT, et al. Cortical thickness atrophy in the transentorhinal cortex in mild cognitive impairment. Neurolmage Clinical. 2018/12/05. 2019;21:101617. Available from: https://www.ncbi.nlm.nih.gov/pubmed/30552075.

125. Dickerson BC, Bakkour A, Salat DH, Feczko E, Pacheco J, Greve DN, et al. The cortical signature of Alzheimer's disease: regionally specific cortical thinning relates to symptom severity in very mild to mild $A D$ dementia and is detectable in asymptomatic amyloid-positive individuals. Cerebral Cortex. 2008;19(3):497-510. Available from: https://doi.org/10.1093/cercor/bhn113.

126. Kälin AM, Park MTM, Chakravarty MM, Lerch JP, Michels L, Schroeder C, et al. Subcortical shape changes, hippocampal atrophy and cortical thinning in future Alzheimer's disease patients. Frontiers in Aging Neuroscience. 2017;9:38. Available from: https://www.frontiersin.org/ article/10.3389/fnagi.2017.00038.

127. Du A-T, Schuff N, Kramer JH, Rosen HJ, Gorno-Tempini ML, Rankin K, et al. Different regional patterns of cortical thinning in Alzheimer's disease and frontotemporal dementia. Brain. 2007;130(4):1159-66. Available from: https://doi.org/10.1093/brain/awm016.

128. Lindberg O, Walterfang M, Looi JCL, Malykhin N, Ostberg P, Zandbelt B, et al. Hippocampal shape analysis in Alzheimer's disease and frontotemporal lobar degeneration subtypes. Journal of Alzheimer's disease : JAD. 2012;30(2):355-65. Available from: https://www.ncbi.nlm.nih.gov/ pubmed/22414571.

129. Wang J, Ekin A, Haan G de. Shape analysis of brain ventricles for improved classification of Alzheimer's patients. In: 2008 15th IEEE International Conference on Image Processing. 2008. p. 2252-5.

130. Berron D, Vieweg P, Hochkeppler A, Pluta JB, Ding S-L, Maass A, et al. A protocol for manual segmentation of medial temporal lobe subregions in 7 Tesla MRI. Neurolmage Clinical. 2017;15:466-82. Available from: https:// www.ncbi.nlm.nih.gov/pubmed/28652965.

131. Wisse LEM, Gerritsen L, Zwanenburg JJM, Kuijf HJ, Luijten PR, Biessels GJ, et al. Subfields of the hippocampal formation at 7 T MRI: in vivo volumetric assessment. Neurolmage. 2012 [cited 2019 Aug 21];61(4):1043-9. Available from: https://www.sciencedirect.com/science/article/pii/S105381191200296 0?via\%3Dihub.

132. Evans TE, Adams HHH, Licher S, Wolters FJ, van der Lugt A, Ikram MK, et al. Subregional volumes of the hippocampus in relation to cognitive function and risk of dementia. Neurolmage. 2018 [cited 2019 Sep 5];178:129-35. Available from: https://www.sciencedirect.com/science/article/pii/S1053811 918304488?via\%3Dihub.

133. Carlesimo GA, Piras F, Orfei MD, lorio M, Caltagirone C, Spalletta G. Atrophy of presubiculum and subiculum is the earliest hippocampal anatomical marker of Alzheimer's disease. Alzheimer's \& dementia (Amsterdam, Netherlands). 2015;1 (1):24-32. Available from: https://www.ncbi.nlm.nih.gov/ pubmed/27239489.

134. Wolk DA, Das SR, Mueller SG, Weiner MW, Yushkevich PA, Initiative ADN. Medial temporal lobe subregional morphometry using high resolution MRI in Alzheimer's disease. Neurobiology of aging. 2016/09/30. 2017; 49:204-13. Available from: https://www.ncbi.nlm.nih.gov/pubmed/27836336.

135. Betts MJ, Acosta-Cabronero J, Cardenas-Blanco A, Nestor PJ, Düzel E. Highresolution characterisation of the aging brain using simultaneous quantitative susceptibility mapping (QSM) and R2* measurements at $7 \mathrm{~T}$. Neurolmage. 2016 [cited 2019 Aug 21];138:43-63. Available from: https:// www.sciencedirect.com/science/article/pii/S1053811916301446?via\%3Dihub.

136. Daugherty AM, Haacke EM, Raz N. Striatal iron content predicts its shrinkage and changes in verbal working memory after two years in healthy adults. J Neurosc. 2015;35(17):6731-43. Available from: https://www.ncbi.nIm.nih.gov/ pubmed/25926451.

137. Ghadery C, Pirpamer L, Hofer E, Langkammer C, Petrovic K, Loitfelder M et al. R2* mapping for brain iron: associations with cognition in normal aging. Neurobiol Aging. 2015 [cited 2019 Aug 21];36(2):925-32. Available from: https:/www.sciencedirect.com/science/article/pii/S0197458014006186 ?via\%3Dihub.

138. Sullivan E v, Adalsteinsson E, Rohlfing T, Pfefferbaum A. Relevance of iron deposition in deep gray matter brain structures to cognitive and motor performance in healthy elderly men and women: exploratory findings. Brain Imaging Behavior. 2009 ;3(2):167-75. Available from: https://www.ncbi.nlm. nih.gov/pubmed/20161183. 
139. Li W, Langkammer C, Chou Y-H, Petrovic K, Schmidt R, Song AW, et al. Association between increased magnetic susceptibility of deep gray matter nuclei and decreased motor function in healthy adults. Neurolmage. 2014/ 10/12. 2015;105:45-52. Available from: https://www.ncbi.nlm.nih.gov/ pubmed/25315786.

140. Acosta-Cabronero J, Williams GB, Cardenas-Blanco A, Arnold RJ, Lupson V, Nestor PJ. In vivo quantitative susceptibility mapping (QSM) in Alzheimer's disease. PloS One. $2013 ; 8(11): e 81093-e 81093$. Available from: https://www. ncbi.nlm.nih.gov/pubmed/24278382.

141. Bartzokis G, Sultzer D, Cummings J, Holt LE, Hance DB, Henderson WW, et al. In vivo evaluation of brain iron in Alzheimer disease using magnetic resonance imaging. Archives General Psychiatry. 2000 [cited 2019 Aug 22];57(1):47-53. Available from: http://www.ncbi.nlm.nih.gov/ pubmed/10632232.

142. Möller HE, Bossoni L, Connor JR, Crichton RR, Does MD, Ward RJ, et al. Iron, myelin, and the brain: neuroimaging meets neurobiology. Vol. 42, Trends in Neurosciences. Elsevier Ltd; 2019. p. 384-401.

143. Bagnato F, Hametner S, Welch EB. Visualizing iron in multiple sclerosis. Magnetic resonance imaging. 2013/01/22. 2013;31(3):376-84. Available from: https://www.ncbi.nlm.nih.gov/pubmed/23347601.

144. Wisnieff C, Ramanan S, Olesik J, Gauthier S, Wang Y, Pitt D. Quantitative susceptibility mapping (QSM) of white matter multiple sclerosis lesions: interpreting positive susceptibility and the presence of iron. Magnetic Resonance Med. 2014/08/18. 2015;74(2):564-70. Available from: https:// www.ncbi.nlm.nih.gov/pubmed/25137340.

145. Ward RJ, Zucca FA, Duyn JH, Crichton RR, Zecca L. The role of iron in brain ageing and neurodegenerative disorders. Lancet Neurol $2014 ; 13(10): 1045-$ 60. Available from: https://www.ncbi.nlm.nih.gov/pubmed/25231526.

146. Acosta-Cabronero J, Cardenas-Blanco A, Betts MJ, Butryn M, Valdes-Herrera JP, Galazky I, et al. The whole-brain pattern of magnetic susceptibility perturbations in Parkinson's disease. Brain. 2016;140(1):118-31. Available from: https://doi.org/10.1093/brain/aww278.

147. Ayton $S$, Fazlollahi $A$, Bourgeat $P$, Raniga $P, N g$ A, Lim $Y Y$, et al. Cerebral quantitative susceptibility mapping predicts amyloid- $\beta$-related cognitive decline. Brain. 2017;140(8):2112-9. Available from: https://doi.org/10.1093/ brain/awx137.

148. Hohenfeld C, Werner CJ, Reetz K. Resting-state connectivity in neurodegenerative disorders: is there potential for an imaging biomarker? Neurolmage: Clinical. 2018 [cited 2019 Aug 15];18:849-70. Available from: https://www.sciencedirect.com/science/article/pii/S2213158218300834.

149. Bayram E, Caldwell JZK, Banks SJ. Current understanding of magnetic resonance imaging biomarkers and memory in Alzheimer's disease. Alzheimer's Dementia. 2018 [cited 2019 Aug 15];4:395-413. Available from: https://www.sciencedirect.com/science/article/pii/\$2352873718300258.

150. Greicius MD, Srivastava G, Reiss AL, Menon V. Default-mode network activity distinguishes Alzheimer's disease from healthy aging: evidence from functional MRI. Proc National Acad Sci U. S. A. 2004;101(13):4637. Available from: http://www.pnas.org/content/101/13/4637.abstract.

151. Dickerson BC, Salat DH, Bates JF, Atiya M, Killiany RJ, Greve DN, et al. Medial temporal lobe function and structure in mild cognitive impairment. Ann Neurol. 2004;56(1):27-35. Available from: https://www.ncbi.nlm.nih.gov/ pubmed/15236399.

152. Seeley WW, Crawford RK, Zhou J, Miller BL, Greicius MD. Neurodegenerative diseases target large-scale human brain networks. Neuron. 2009;62(1):42-52. Available from: https://www.ncbi.nlm.nih.gov/pubmed/19376066.

153. Sperling RA, Laviolette PS, O'Keefe K, O'Brien J, Rentz DM, Pihlajamaki M, et al. Amyloid deposition is associated with impaired default network function in older persons without dementia. Neuron. 2009;63(2):178-88. Available from: https://www.ncbi.nlm.nih.gov/pubmed/19640477.

154. Vannini P, Hedden T, Becker JA, Sullivan C, Putcha D, Rentz D, et al. Age and amyloid-related alterations in default network habituation to stimulus repetition. Neurobiol Aging. 2011/02/18. 2012 ;33(7):1237-52. Available from: https://www.ncbi.nlm.nih.gov/pubmed/21334099.

155. Bakker A, Albert MS, Krauss G, Speck CL, Gallagher M. Response of the medial temporal lobe network in amnestic mild cognitive impairment to therapeutic intervention assessed by fMRI and memory task performance. Neurolmage: Clinical. 2015 [cited 2019 Aug 15];7:688-98. Available from: https://www.sciencedirect.com/science/article/pii/S2213158215000273.

156. Leal SL, Landau SM, Bell RK, Jagust WJ. Hippocampal activation is associated with longitudinal amyloid accumulation and cognitive decline. eLife. 2017;6: e22978. Available from: https://www.ncbi.nlm.nih.gov/pubmed/28177283.
157. Huijbers W, Schultz AP, Papp K V, LaPoint MR, Hanseeuw B, Chhatwal JP, et al. Tau accumulation in clinically normal older adults is associated with hippocampal hyperactivity. J Neurosci. 2018/11/27. 201939(3):548-56. Available from: https://www.ncbi.nlm.nih.gov/pubmed/30482786.

158. Maass A, Berron D, Harrison TM, Adams JN, la Joie R, Baker S, et al. Alzheimer's pathology targets distinct memory networks in the ageing brain. Brain. 2019;142(8):2492-509. Available from: https://doi.org/10.1093/ brain/awz154.

159. Bookheimer SY, Strojwas MH, Cohen MS, Saunders AM, Pericak-Vance MA, Mazziotta JC, et al. Patterns of brain activation in people at risk for Alzheimer's disease. New England J Med 2000;343(7):450-6. Available from: https://doi.org/10.1056/NEJM200008173430701.

160. Foster CM, Kennedy KM, Horn MM, Hoagey DA, Rodrigue KM. Both hyperand hypo-activation to cognitive challenge are associated with increased beta-amyloid deposition in healthy aging: a nonlinear effect. Neurolmage. 2018 [cited 2019 Aug 15];166:285-92. Available from: https://www. sciencedirect.com/science/article/pii/S1053811917309060.

161. Celone KA, Calhoun VD, Dickerson BC, Atri A, Chua EF, Miller SL, et al. Alterations in memory networks in mild cognitive impairment and Alzheimer's disease: an independent component analysis. J Neurosci. 2006;26(40):10222. Available from: http://www.jneurosci.org/content/26/4 0/10222.abstract.

162. Haller S, Zaharchuk G, Thomas DL, Lovblad K-O, Barkhof F, Golay X. Arterial spin labeling perfusion of the brain: emerging clinical applications. Radiology. 2016;281(2):337-56. Available from: https://doi.org/10.1148/radiol. 2016150789.

163. Petcharunpaisan S, Ramalho J, Castillo M. Arterial spin labeling in neuroimaging. World J Radiol. 2010;2(10):384-98. Available from: https:// www.ncbi.nlm.nih.gov/pubmed/21161024.

164. Anazodo UC, Finger E, Kwan BYM, Pavlosky W, Warrington JC, Günther M, et al. Using simultaneous PET/MRI to compare the accuracy of diagnosing frontotemporal dementia by arterial spin labelling MRI and FDG-PET. Neurolmage: Clinical. 2018;17:405-14 Available from: http://www. sciencedirect.com/science/article/pii/S2213158217302747.

165. Du AT, Jahng GH, Hayasaka S, Kramer JH, Rosen HJ, Gorno-Tempini ML, et al. Hypoperfusion in frontotemporal dementia and Alzheimer disease by arterial spin labeling MRI. Neurology. 2006;67(7):1215-20 Available from: https://www.ncbi.nlm.nih.gov/pubmed/17030755.

166. Wandell BA. Clarifying human white matter. Annual Review Neurosci. 2016 ;39(1):103-28. Available from: https://doi.org/10.1146/annurev-neuro-070815013815

167. Filley CM, Fields RD. White matter and cognition: making the connection. J Neurophysiol. 2016/08/10. 2016;116(5):2093-104. Available from: https:// www.ncbi.nlm.nih.gov/pubmed/27512019.

168. Soares JM, Marques $P$, Alves $V$, Sousa N. A hitchhiker's quide to diffusion tensor imaging. Front Neurosci 2013;7:31. Available from: https://www.ncbi. nlm.nih.gov/pubmed/23486659.

169. Acosta-Cabronero J, Nestor PJ. Diffusion tensor imaging in Alzheimer's disease: insights into the limbic-diencephalic network and methodological considerations. Front Aging Neurosci. 2014;6:266. Available from: https:// www.ncbi.nlm.nih.gov/pubmed/25324775.

170. Teipel S, Drzezga A, Grothe MJ, Barthel H, Chételat G, Schuff N, et al. Multimodal imaging in Alzheimer's disease: validity and usefulness for early detection. Lancet Neurol 2015 [cited 2019 Aug 16];14(10):1037-53. Available from: https://www.sciencedirect.com/science/article/pii/S147444221500093 9?via\%3Dihub.

171. Mayo CD, Garcia-Barrera MA, Mazerolle EL, Ritchie LJ, Fisk JD, Gawryluk JR, et al. Relationship between DTI metrics and cognitive function in Alzheimer's disease. Front Aging neuroscience. 2019;10:436. Available from: https://www.ncbi.nlm.nih.gov/pubmed/30687081.

172. Song Z, Farrell ME, Chen X, Park DC. Longitudinal accrual of neocortical amyloid burden is associated with microstructural changes of the fornix in cognitively normal adults. Neurobiol Aging. 2018/03/06. 2018;68:114-22. Available from: https://www.ncbi.nlm.nih.gov/pubmed/29602495.

173. Tang M, Chen X, Zhou Q, Liu B, Liu Y, Liu S, et al. Quantitative assessment of amyotrophic lateral sclerosis with diffusion tensor imaging in 3.0T magnetic resonance. International journal of clinical and experimental medicine. 2015;8(5):8295-303. Available from: https://www.ncbi.nlm.nih.gov/ pubmed/26221413.

174. Jones DK, Knösche TR, Turner R. White matter integrity, fiber count, and other fallacies: the do's and don'ts of diffusion MRI. Neurolmage. 2013 [cited 
2019 Aug 16];73:239-54. Available from: https://www.sciencedirect.com/ science/article/pii/S1053811912007306?via\%3Dihub.

175. Mulders PC, van Eijndhoven PF, Beckmann CF. Identifying large-scale neural networks using fMRI. Systems Neuroscience in Depression. 2016 [cited 2019 Aug 16];209-37. Available from: https://www.sciencedirect.com/science/ article/pii/B9780128024560000078.

176. Dwyer DB, Harrison BJ, Yücel M, Whittle S, Zalesky A, Pantelis C, et al. Adolescent cognitive control: brain network dynamics. Stress: Concepts, Cognition, Emotion, and Behavior. 2016 [cited 2019 Aug 16];177-85. Available from: https://www. sciencedirect.com/science/article/pii/B9780128009512000212.

177. Bullmore E, Sporns O. Complex brain networks: graph theoretical analysis of structural and functional systems. Nature Reviews Neurosci. 2009;10:186. Available from: https://doi.org/10.1038/nrn2575.

178. Fornito A, Bullmore ET. Connectomics: a new paradigm for understanding brain disease. European Neuropsychopharmacology. 2015 [cited 2019 Aug 16];25(5):733-48. Available from: https://www.sciencedirect.com/science/ article/pii/S0924977X14000807?via\%3Dihub.

179. Pereira JB, van Westen D, Stomrud E, Strandberg O, Volpe G, Westman E, et al. Abnormal structural brain connectome in individuals with preclinical Alzheimer's disease. Alzheimer's Dementia. 2017 [cited 2019 Aug 16];13(7): P7. Available from: https://www.sciencedirect.com/science/article/pii/ S1552526017328832

180. Çiftçi K. Minimum spanning tree reflects the alterations of the default mode network during Alzheimer's disease. Ann Biomed Engi 2011;39(5):1493-504 Available from: https://doi.org/10.1007/s10439-011-0258-9.

181. Pereira JB, Strandberg TO, Palmqvist S, Volpe G, van Westen D, Westman E, et al. Amyloid network topology characterizes the progression of Alzheimer's disease during the predementia stages. Cerebral cortex (New York, NY : 1991). 2018;28(1):340-9. Available from: https://www.ncbi.nlm.nih. gov/pubmed/29136123.

182. Mårtensson G, Pereira JB, Mecocci P, Vellas B, Tsolaki M, Kłoszewska I, et al. Stability of graph theoretical measures in structural brain networks in Alzheimer's disease. Scientific Reports. 2018:8(1):11592 Available from: https://doi.org/10.1038/s41598-018-29927-0.

183. Pellegrini E, Ballerini L, Hernandez MDCV, Chappell FM, González-Castro V, Anblagan $D$, et al. Machine learning of neuroimaging for assisted diagnosis of cognitive impairment and dementia: a systematic review. Alzheimer's Dementia (Amsterdam, Netherlands). 2018;10:519-35. Available from: https://www.ncbi.nlm.nih.gov/pubmed/30364671.

184. Mirzaei G, Adeli A, Adeli H. Imaging and machine learning techniques for diagnosis of Alzheimer's disease. Reviews in the neurosciences. 2016 [cited 2019 Aug 16];27(8):857-70. Available from: http://www.ncbi.nlm.nih.gov/ pubmed/27518905.

185. Salvatore C, Battista P, Castiglioni I. Frontiers for the early diagnosis of AD by means of MRI brain imaging and support vector machines. Current Alzheimer Research. 2016 [cited 2019 Aug 16];13(5):509-33. Available from: http://www.ncbi.nlm.nih.gov/pubmed/26567735.

186. Tohka J, Moradi E, Huttunen H, Initiative ADN. Comparison of feature selection techniques in machine learning for anatomical brain MRI in dementia. Neuroinformatics. 2016;14(3):279-96. Available from: https://doi. org/10.1007/s12021-015-9292-3

187. Dimitriadis SI, Liparas D, Initiative ADN. How random is the random forest? Random forest algorithm on the service of structural imaging biomarkers for Alzheimer's disease: from Alzheimer's disease neuroimaging initiative (ADNI) database. Neural Regeneration Res. 2018;13(6):962-70. Available from: https://www.ncbi.nlm.nih.gov/pubmed/29926817.

188. Lee JS, Kim C, Shin J-H, Cho H, Shin D-S, Kim N, et al. Machine learningbased individual assessment of cortical atrophy pattern in Alzheimer's disease spectrum: development of the classifier and longitudinal evaluation. Scientific Reports. 2018;8(1):4161 Available from: https://www.ncbi.nlm.nih. gov/pubmed/29515131.

189. Hurtz S, Chow N, Watson AE, Somme JH, Goukasian N, Hwang KS, et al. Automated and manual hippocampal segmentation techniques: comparison of results, reproducibility and clinical applicability. Neurolmage: Clinical. 2019 [cited 2019 Aug 16];21:101574. Available from: https://www. sciencedirect.com/science/article/pii/S221315821830322X.

190. Mehdipour Ghazi M, Nielsen M, Pai A, Cardoso MJ, Modat M, Ourselin S, et al. Training recurrent neural networks robust to incomplete data: application to Alzheimer's disease progression modeling. Medical Image Analysis. 2019 [cited 2019 Aug 16];53:39-46. Available from: https://www. sciencedirect.com/science/article/abs/pii/S136184151830598X.
191. Wang Y, Xu C, Park J-H, Lee S, Stern Y, Yoo S, et al. Diagnosis and prognosis of Alzheimer's disease using brain morphometry and white matter connectomes. Neurolmage: Clin. 2019 [cited 2019 Aug 16];23:101859. Available from: https://www.sciencedirect.com/science/article/pii/\$221315 8219302098?via\%3Dihub.

192. Moscoso A, Silva-Rodríguez J, Aldrey JM, Cortés J, Fernández-Ferreiro A, Gómez-Lado N, et al. Prediction of Alzheimer's disease dementia with MRI beyond the short-term: implications for the design of predictive models. Neurolmage: Clin. 2019 [cited 2019 Aug 16];23:101837. Available from: https://www.sciencedirect.com/science/article/pii/S2213158219301871 ?via\%3Dihub.

193. Bouts MJRJ, van der Grond J, Vernooij MW, Koini M, Schouten TM, de Vos F, et al. Detection of mild cognitive impairment in a community-dwelling population using quantitative, multiparametric MRI-based classification. Human Brain Mapping. 2019/02/25. 2019;40(9):2711-22. Available from: https://www.ncbi.nlm.nih.gov/pubmed/30803110.

194. Lian C, Liu M, Zhang J, Shen D. Hierarchical fully convolutional network for joint atrophy localization and Alzheimer's disease diagnosis using structural MRI. IEEE Trans Pattern Anal Mach Intell. 2018;1.

195. Li F, Liu M. Alzheimer's disease diagnosis based on multiple cluster dense convolutional networks. Computerized Medical Imaging and Graphics. 2018 [cited 2019 Aug 16];70:101-10. Available from: https://www.sciencedirect. com/science/article/abs/pii/S089561111830199X.

196. Hojjati SH, Ebrahimzadeh A, Khazaee A, Babajani-Feremi A. Predicting conversion from $\mathrm{MCl}$ to $\mathrm{AD}$ by integrating rs-fMRI and structural MRI. Comput Biol and Medicine. 2018 [cited 2019 Aug 16];102:30-9. Available from: https://www.sciencedirect.com/science/article/pii/S0010482518302609.

197. Ruiz E, Ramírez J, Górriz JM, Casillas J, Alzheimer's Disease Neuroimaging Initiative. Alzheimer's disease computer-aided diagnosis: histogram-based analysis of regional MRI volumes for feature selection and classification. J Alzheimer's Dis. 2018 [cited 2019 Aug 16];65(3):819-42. Available from: http://www.ncbi.n/m.nih.gov/pubmed/29966190.

198. Gómez-Sancho M, Tohka J, Gómez-Verdejo V. Comparison of feature representations in MRI-based MCl-to-AD conversion prediction. Magnetic Resonance Imaging. 2018 [cited 2019 Aug 16];50:84-95. Available from: https://www.sciencedirect.com/science/article/abs/pii/S0730725X18300286 ?via\%3Dihub.

199. Salvatore C, Castiglioni I. A wrapped multi-label classifier for the automatic diagnosis and prognosis of Alzheimer's disease. J Neurosci Methods. 2018 [cited 2019 Aug 16];302:58-65. Available from: https://www.sciencedirect. com/science/article/pii/S016502701730434X.

200. Cárdenas-Peña D, Collazos-Huertas D, Castellanos-Dominguez G. Enhanced data representation by kernel metric learning for dementia diagnosis. Front Neurosci. 2017;11:413. Available from: https://www.ncbi.nlm.nih.gov/ pubmed/28798659.

201. Ardekani BA, Bermudez E, Mubeen AM, Bachman AH, Alzheimer's Disease Neuroimaging Initiative. Prediction of incipient Alzheimer's disease dementia in patients with mild cognitive impairment. J Alzheimer's Dis. 2017 [cited 2019 Aug 16];55(1):269-81. Available from: http://www.ncbi.nlm. nih.gov/pubmed/27662309.

202. Wang S, Zhang Y, Liu G, Phillips P, Yuan T-F. Detection of Alzheimer's disease by three-dimensional displacement field estimation in structural magnetic resonance imaging. JournalAlzheimer's Dis. 2016 ;50(1):233-48. [cited 2019 Aug 16] Available from: http://www.ncbi.nlm.nih.gov/ pubmed/26682696.

203. Ge C, Qu Q, Gu IY-H, Jakola AS. Multi-stream multi-scale deep convolutional networks for Alzheimer's disease detection using MR images. Neurocomputing. 2019;350:60-9 [cited 2019 Aug 16] Available from: https:// www.sciencedirect.com/science/article/pii/S0925231219305478.

204. Cui R, Liu M. RNN-based longitudinal analysis for diagnosis of Alzheimer's disease. Comput Med Imaging Graphics. 2019;73:1-10. [cited 2019 Aug 16] Available from: https://www.sciencedirect.com/science/article/abs/pii/ S0895611118303987

205. Duraisamy B, Shanmugam JV, Annamalai J. Alzheimer disease detection from structural MR images using FCM based weighted probabilistic neural network. Brain Imaging Behavior., Available from. 2019;13(1):87-110 https:// doi.org/10.1007/s11682-018-9831-2.

206. Bi X, Li S, Xiao B, Li Y, Wang G, Ma X. Computer aided Alzheimer's disease diagnosis by an unsupervised deep learning technology. Neurocomputing 2019 [cited 2019 Aug 16]; Available from: https://www.sciencedirect.com/ science/article/pii/S0925231219304709. 
207. Zeng N, Qiu H, Wang Z, Liu W, Zhang H, Li Y. A new switching-delayedPSO-based optimized SVM algorithm for diagnosis of Alzheimer's disease. Neurocomputing. 2018;320:195-202 [cited 2019 Aug 16] Available from: https://www.sciencedirect.com/science/article/pii/S0925231218310531.

208. Hosseini-Asl E, Ghazal M, Mahmoud A, Aslantas A, Shalaby AM, Casanova MF, et al. Alzheimer's disease diagnostics by a 3D deeply supervised adaptable convolutional network. Front Biosci. 2018;23:584-96 [cited 2019 Aug 16] Available from: http://www.ncbi.nlm.nih.gov/pubmed/28930562.

209. Khajehnejad M, Saatlou FH, Mohammadzade H. Alzheimer's disease early diagnosis using manifold-based semi-supervised learning. Brain Sci. 2017; 7(8):109 Available from: https://www.ncbi.nlm.nih.gov/pubmed/28825647.

210. Ahmed O ben, Benois-Pineau J, Allard M, Catheline G, Amar C ben. Recognition of Alzheimer's disease and mild cognitive impairment with multimodal image-derived biomarkers and multiple kernel learning. Neurocomputing. $2017 ; 220: 98-110$. [cited 2019 Aug 16] Available from: https://www.sciencedirect.com/science/article/pii/S0925231216308967.

211. Luo S, Li X, Li J. Automatic Alzheimer's fisease recognition from MRI data dsing deep learning method. J Appl Mathematics Physics. 2017;05(09):1892-8.

212. Demirhan A. Classification of structural MRI for detecting Alzheimer's disease. International Journal of Intelligent Systems and Applications in Engineering. 2016 26;0(0). Available from: https://www.ijisae.org/IJISAE/ article/view/959.

213. Chen Y, Sha M, Zhao X, Ma J, Ni H, Gao W, et al. Automated detection of pathologic white matter alterations in Alzheimer's disease using combined diffusivity and kurtosis method. Psychiatry Research: Neuroimaging. 2017; 264:35-45 [cited 2019 Aug 16] Available from: https://www.sciencedirect. com/science/article/pii/S092549271630186X.

214. Basaia S, Agosta F, Wagner L, Canu E, Magnani G, Santangelo R, et al. Automated classification of Alzheimer's disease and mild cognitive impairment using a single MRI and deep neural networks. Neurolmage Clin. 2018/12/18. 2019;21:101645. Available from: https://www.ncbi.nlm.nih.gov/ pubmed/30584016.

215. Liu M, Cheng D, Wang K, Wang Y, Initiative the ADN. Multi-modality cascaded convolutional neural networks for Alzheimer's disease diagnosis. Neuroinformatics, Available from. 2018;16(3):295-308 https://doi.org/10. 1007/s12021-018-9370-4.

216. Zhang Y, Liu S. Analysis of structural brain MRI and multi-parameter classification for Alzheimer's disease. Biomedizinische Technik Biomed Eng. 2018;63(4):427-37 [cited 2019 Aug 16] Available from: http://www.ncbi.nlm. nih.gov/pubmed/28622141.

217. Spasov S, Passamonti L, Duggento A, Liò P, Toschi N. A parameter-efficient deep learning approach to predict conversion from mild cognitive impairment to Alzheimer's disease. Neurolmage. 2019;189:276-87 [cited 2019 Aug 16] Available from: https://www.sciencedirect.com/science/article/ pii/S105381191930031X.

218. Sun Z, Qiao Y, Lelieveldt BPF, Staring M. Integrating spatial-anatomical regularization and structure sparsity into SVM: Improving interpretation of Alzheimer's disease classification. Neurolmage. 2018;178:445-60 [cited 2019 Aug 16] Available from: https://www.sciencedirect.com/science/article/pii/S1 053811918304658.

219. Kim JP, Kim J, Park YH, Park SB, Lee JS, Yoo S, et al. Machine learning based hierarchical classification of frontotemporal dementia and Alzheimer's disease. Neurolmage Clin. 2019;23:101811 Available from: https://www.ncbi. nlm.nih.gov/pubmed/30981204.

220. Neffati S, ben Abdellafou K, Jaffel I, Taouali O, Bouzrara K. An improved machine learning technique based on downsized KPCA for Alzheimer's disease classification. Int J Imaging Syst Technol. 2019;29(2):121-31. Available from: https://doi.org/10.1002/ima.22304.

221. Singh G, Samavedham L, Lim EC-H. Determination of imaging biomarkers to decipher disease trajectories and differential diagnosis of neurodegenerative diseases (Dlsease TreND). J Neurosci Methods. 2018;305: 105-16 [cited 2019 Aug 16] Available from: https://www.sciencedirect.com/ science/article/pii/S0165027018301407?via\%3Dihub.

222. Asim Y, Raza B, Malik AK, Rathore S, Hussain L, Iftikhar MA. A multi-modal, multi-atlas-based approach for Alzheimer detection via machine learning. Int J Imaging Syst Technol. 2018 1;28(2):113-23. Available from: https://doi. org/10.1002/ima.22263.

223. Lu D, Popuri K, Ding GW, Balachandar R, Beg MF, Initiative ADN. Multimodal and multiscale deep neural networks for the early diagnosis of Alzheimer's disease using structural MR and FDG-PET images. Scientific Reports. 2018; 8(1):5697 Available from: https://www.ncbi.nlm.nih.gov/pubmed/29632364.
224. Yan Y, Somer E, Grau V. Classification of amyloid PET images using novel features for early diagnosis of Alzheimer's disease and mild cognitive impairment conversion. Nuclear Med Commun. 2019;40(3):242-8 [cited 2019 Aug 16] Available from: http://www.ncbi.nlm.nih.gov/pubmed/30507747.

225. An L, Adeli E, Liu M, Zhang J, Lee S-W, Shen D. A hierarchical feature and sample selection framework and its application for Alzheimer's disease diagnosis. Scientific Reports. 2017;7:45269 Available from: https://doi.org/10. 1038/srep45269.

226. Ahmed RM, Devenney EM, Irish M, Ittner A, Naismith S, Ittner LM, et al. Neuronal network disintegration: common pathways linking neurodegenerative diseases. J Neurol Neurosurg Psychiatry. 2016;87(11):1234 Available from: http://jnnp.bmj.com/content/87/11/1234.abstract.

\section{Publisher's Note}

Springer Nature remains neutral with regard to jurisdictional claims in published maps and institutional affiliations. 